\title{
A Single-Stage Buck-Boost Three-Level Neutral-Point-Clamped Inverter with Two Input Sources for the Grid-Tied Photovoltaic Power Generation
}

\author{
Xuefeng Ge $\mathbb{D}^{1},{ }^{1}$ Mengxing Chen, ${ }^{2}$ Mingming Shi, ${ }^{1}$ Qi Zhou, ${ }^{1}$ Juan Li, ${ }^{1}$ Di Huang, \\ Xiaodong Yuan, ${ }^{1}$ and Yubo Yuan ${ }^{1}$ \\ ${ }^{1}$ State Grid Jiangsu Electric Power Co., Ltd. Research Institute, Nanjing, China \\ ${ }^{2}$ The Department of Energy Technology, Aalborg University, Aalborg, Denmark
}

Correspondence should be addressed to Xuefeng Ge; gexuefeng.2008@163.com

Received 21 October 2018; Revised 7 January 2019; Accepted 15 January 2019; Published 2 April 2019

Academic Editor: Gareth A. Vio

Copyright (C) 2019 Xuefeng Ge et al. This is an open access article distributed under the Creative Commons Attribution License, which permits unrestricted use, distribution, and reproduction in any medium, provided the original work is properly cited.

\begin{abstract}
This paper proposes a novel single-stage buck-boost three-Level neutral-point-clamped (NPC) inverter with two independent dc sources coupled for the grid-tied photovoltaic (PV) application, which can effectively solve the unbalanced operational conditions generally appearing between two independent PV sources. The proposed control scheme can simultaneously guarantee the maximum power point (MPP) operation of both PV sources and maintain the output waveform quality. Compared to the traditional two-stage PV inverter, the proposed NPC inverter could reduce the PV array voltage requirement and the voltage rating of dclink capacitors; also it shows advantages in operational efficiency. MATLAB simulations and experimental results are presented to examine the performance of the proposed three-level NPC inverter.
\end{abstract}

\section{Introduction}

Recently, photovoltaic (PV) power generations are widely applied in the distribution network. The PV power generation system can be classified into two main categories of gridtied and off-grid systems, and the grid-tied system dominates the PV applications in terms of the generation capacity. To date, most of the applied PV converters are two-level inverter, whose main shortcomings are high operation voltage and low operational efficiency $[1,2]$. For the purpose of increasing power conversion efficiency, the multilevel converters are preferably assumed as the interfacing converter between the PV array and the distribution grid due to its inherent operational characteristics [3-7], such as the reduced voltage stress, low harmonic distortion, low electro-magnetic interference (EMI), and reduced current rating. Moreover, the mature 1500 V PV panel in commercial allows PV systems to be integrated into the high voltage grid without the galvanic isolation using the multilevel converters $[8,9]$. Besides, the common two-level inverter utilizes buck topology, thus a step-up transformer is mandatory at the grid-side, which would increase the size and cost of the PV generation system. At present, the two-stage neutral-point-clamped (NPC) inverter has been widely used in industry as the interfacing converter in dozens of $\mathrm{kW}$ PV applications, whose circuit diagram is drawn in Figure 1. Two dc-dc boost converters are directly connected to the upper and lower dc rails of a traditional NPC inverter.

For the effort of making a compact design, this paper proposes a novel single-stage buck-boost three-level NPC inverter as the interfacing circuit to tie separated PV arrays to grid. In addition, the proposed control method can individually track the MPP for each PV array and boost the PV voltages to a higher dc-link voltage. The upper/lower dclink voltages are also balanced by adjusting the switching states of NPC inverter, which could guarantee the grid-side current quality.

Compared to the two-stage NPC inverter, the proposed inverter saves two diodes and exhibits lower voltage rating of dc-link capacitors as well as lower voltage rating of front-end switches. Moreover, the proposed inverter exhibits higher efficiency under high voltage boosting ratio condition. 


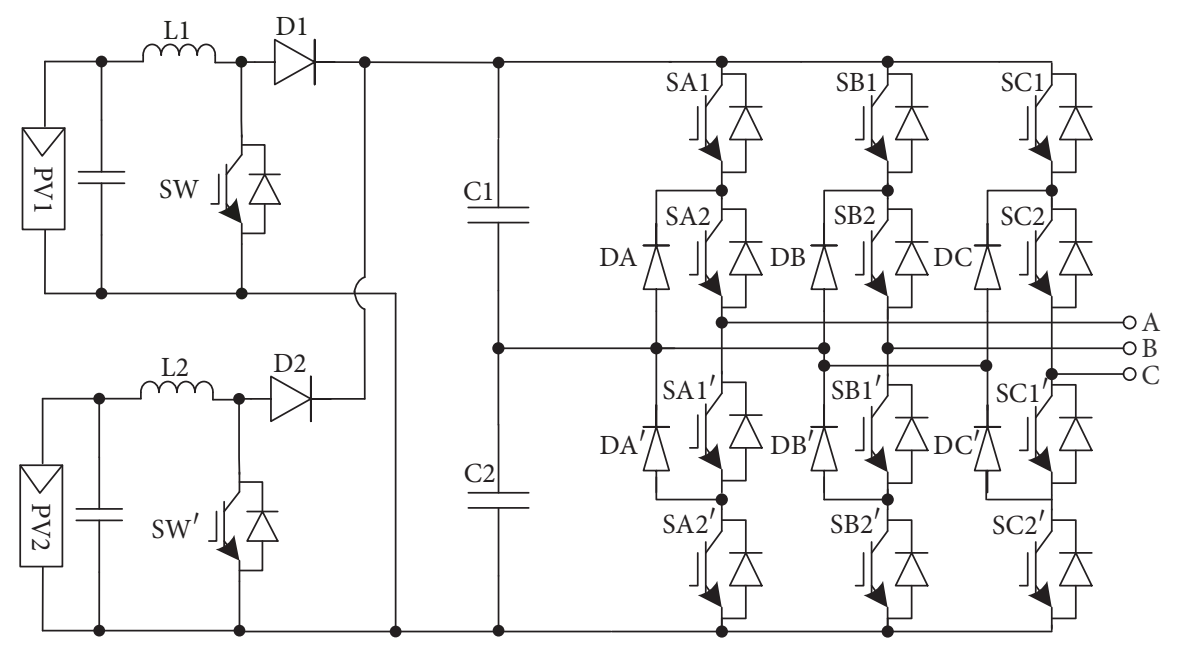

FIgURE 1: Topology of two-stage three-level NPC inverter.

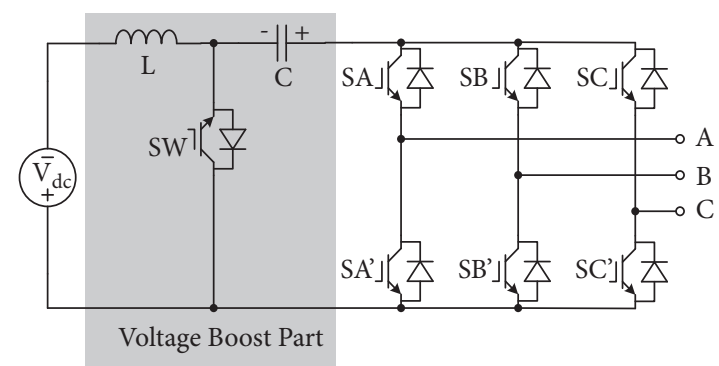

(a)

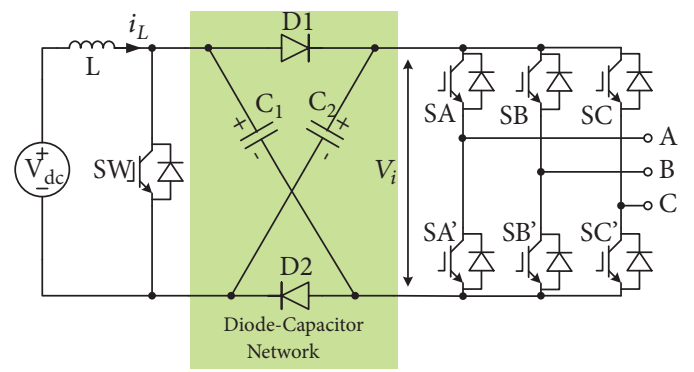

(b)

Figure 2: Topologies of (a) Ćuk-derived and (b) diode-assisted buck-boost two-level inverter.

Theoretical analysis has been done in Section 5 to compare the proposed inverter with two-stage NPC inverter in terms of operational efficiency. Finally, MATLAB simulations and experimental prototype verified the performance of the proposed three-level inverter.

\section{Review of Single-Stage Buck-Boost Inverters}

2.1. Single-Stage Buck-Boost Two-Level Inverters. Figure 2(a) shows the Cuk-derived buck-boost two-level inverter [10], where capacitor $\mathrm{C}$, switch SW, and inductor L form the voltage boosting part. The voltage boosting part, functioning as the energy storage and delivering intermediate, operates in particular with two distinct states defined by ON and OFF states of SW. The following equation for the Cuk-derived buck-boost two-level inverter can be obtained:

$$
\frac{V_{g}}{V_{d c}}=\frac{M}{2(1-k)}
$$

where $V_{g}$ refers to the amplitude of grid phase voltage, $V_{d c}$ refers to the DC source input voltage, $M$ refers to the modulation index, and $k$ refers to the duty ratio of switch SW. Specifically, the ratio value $\left(V_{g} / V_{d c}\right)$ is named as voltage boosting ratio, which demonstrates the inverter's voltage boosting capability from DC input voltage to grid voltage amplitude.

Figure 2(b) shows another type of single-stage buckboost two-level inverter named as the diode-assisted buckboost inverter [11]. The main difference between the Cukderived inverter and the diode-assisted inverter is that the diode-assisted inverter contains one more diode and capacitor to form the X-shaped diode-capacitor network, which could increase the dc-link voltage doubly. And the voltage boosting ratio of the diode-assisted buck-boost inverter can be derived as:

$$
\frac{V_{g}}{V_{d c}}=\frac{M}{1-k}
$$

According to (1) and (2), it is noted that the diode-assisted buck-boost inverter has a higher voltage boosting ratio and it also shows a higher operational efficiency under certain voltage boosting ratio than the traditional two-stage buckboost inverter [12].

Besides, Figure 3 shows the topology of traditional two-level Z-source inverter [13-15], where the X-shaped capacitor-inductor network couples the rear-end inverter circuit and dc source. The unique shoot-through state of Zsource inverter provides the voltage boosting function. The 


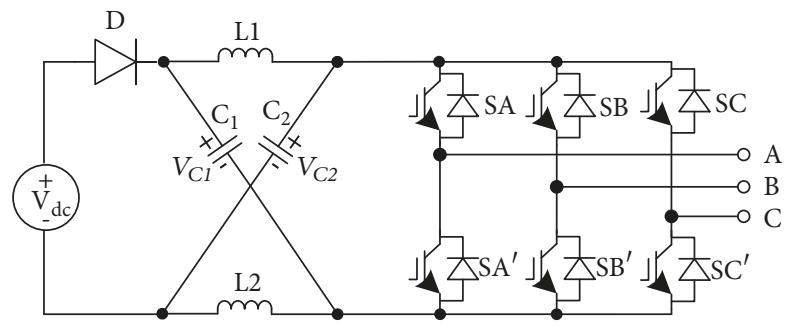

FIgURE 3: Topology of two-level Z-source inverter.

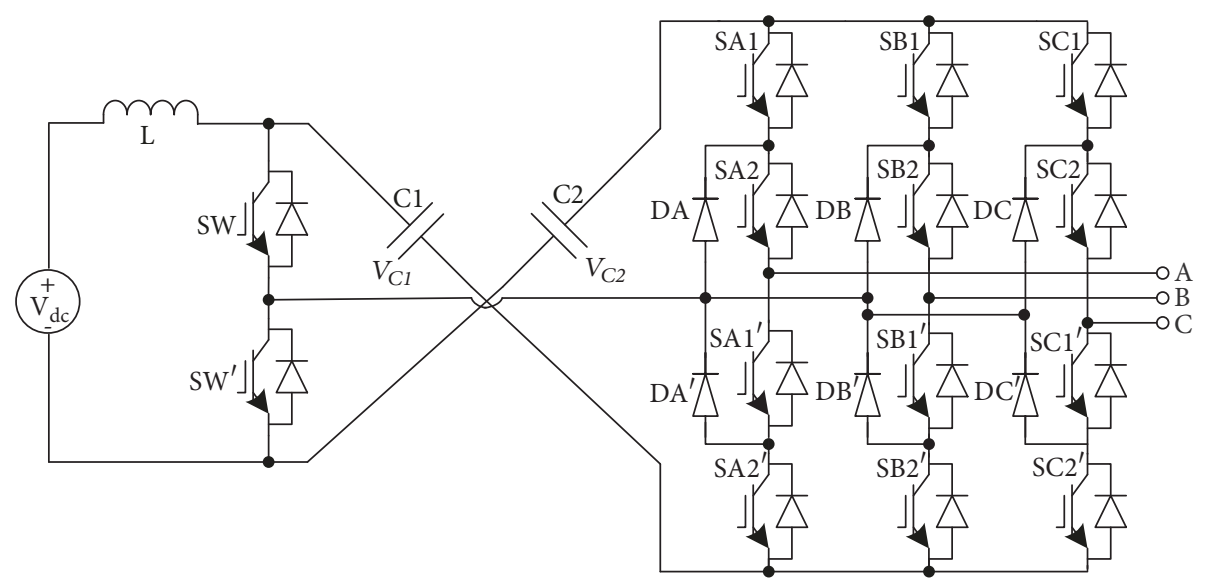

FIgURE 4: Topology of AE-NPC inverter.

voltage boosting ratio of two-level Z-source inverter can be expressed as

$$
\frac{V_{g}}{V_{d c}}=\frac{M}{2\left(1-T_{0} / T\right)}
$$

where $T$ refers to the switching cycle of $\mathrm{Z}$-source inverter and $T_{0}$ represents the shoot-through duration.

The quasi-Z-source inverter was firstly presented in [16, 17] and the main advantage of the quasi-Z-source converter is lower dc capacitor voltage due to the specific embeddeddc-source circuit. Furthermore, the switched-inductor with the quasi-Z-source converter could increase the boost factor by increasing few elements [18]. The other derive topologies of Z-source converter, consisting of Trans-Z-source, Semi-Zsource $[19,20]$, are performed with the higher boost factor and lower voltage stress of the devices.

2.2. Single-Stage Buck-Boost Multilevel Inverters. Based on the single-stage buck-boost two-level converters, the buckboost multilevel inverters were proposed in [21-24] to increase power conversion efficiency. Among them, the amplitude enhanced buck-boost NPC (AE-NPC) inverter presented in [24] is representative. Figure 4 shows the topology of AE-NPC inverter, which can enhance the voltage boosting ratio and balance the dc-link voltages by controlling the front-end switches SW and SW'. The voltage boosting ratio $\left(V_{g} / V_{d c}\right)$ of AE-NPC inverter is the same as (2).

However, the single-stage inverters shown in Figures 2-4 utilize single dc source to power the buck-boost power generation. When implemented in PV generation system, these single-stage inverters cannot effectively handle the power reduction induced by the mismatching of separate PV panels.

To further explore the buck-boost three-level inversion technique in grid-tied PV application, this paper proposes a novel dual-source AE-NPC topology to couple two separate PV sources and a NPC inverter. The corresponding topological and control illustrations of the proposed inverter will be presented in the following sections.

\section{Topological Illustration and Operational Principle of Dual-Source AE-NPC Inverter}

The proposed dual-source AE-NPC three-level inverter with two input PV arrays is shown in Figure 5, and the voltage boosting part consists of two switches and inductors. Compared with the buck-boost inverter shown in Figure 4, an additional inductor is added in shunt to conduct source current in case of unequal PV currents. Two switches SW and SW' are directly connected to the PV sources, being different from Figure 4 so that two separate PV sources can be controlled independently. Furthermore, the proposed inverter topology could save two diodes when compared with the twostage NPC inverter.

The equivalent circuits are shown in Figure 6 to describe operating modes of the proposed inverter more specifically. The first operating mode $\left\{\mathrm{SW}=1\right.$ and $\left.\mathrm{SW}^{\prime}=0\right\}$ is shown in Figure 6(a), where the inductor L1 is charged by the source 


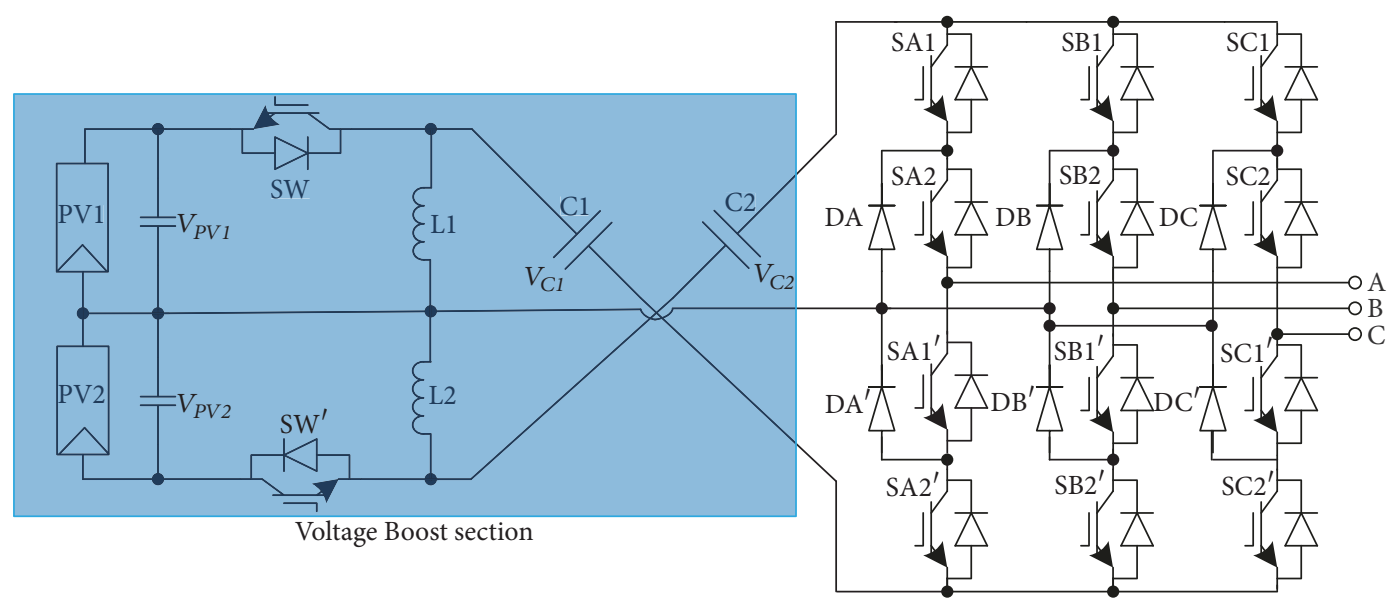

FIgURE 5: Topology of dual-source AE-NPC inverter.

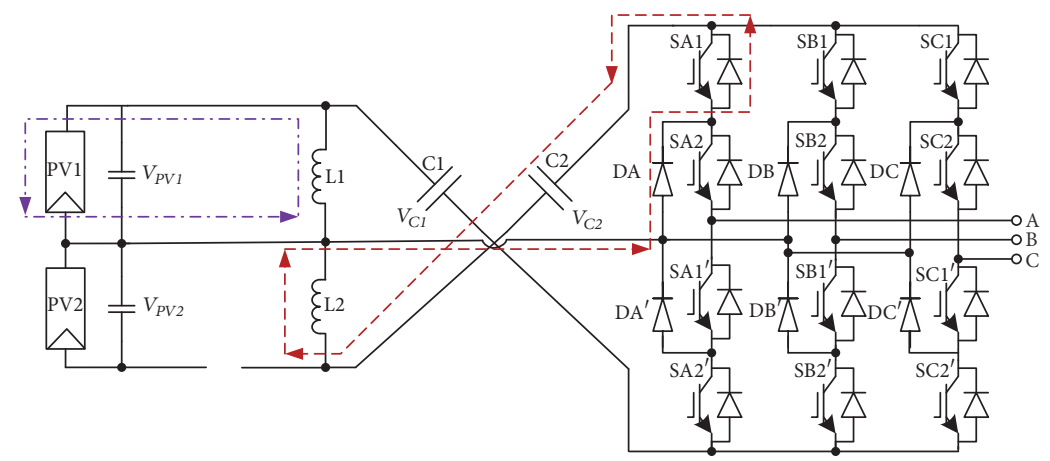

(a)

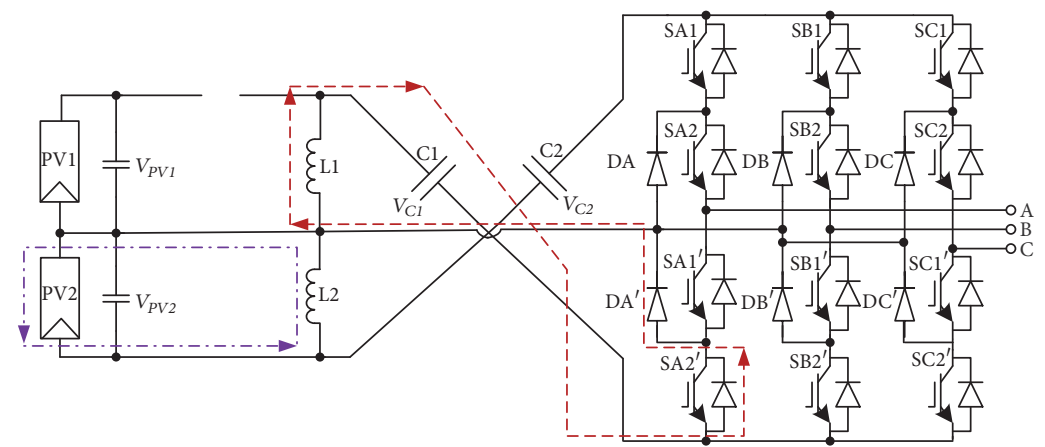

(b)

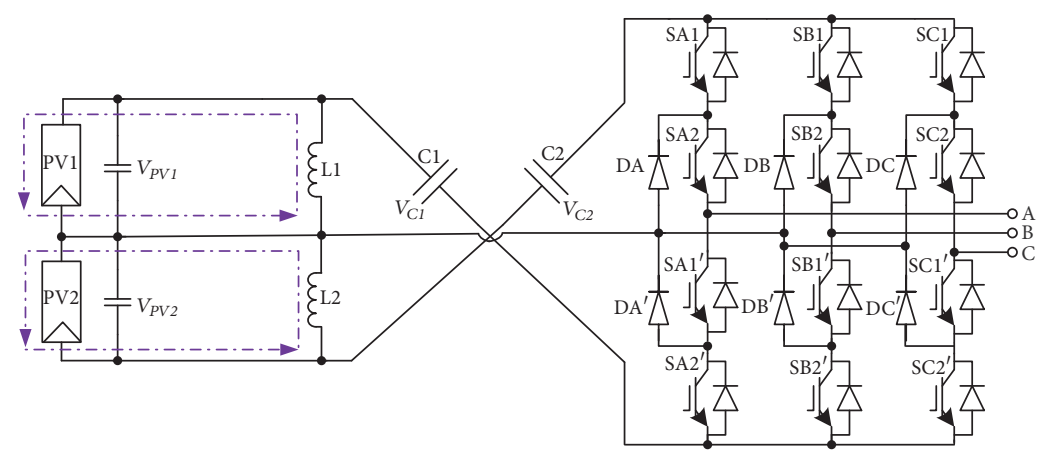

(c)

FIGURE 6: Equivalent circuits of dual-source AE-NPC inverter when (a) SW = ON and SW' $=$ OFF, (b) SW = OFF and SW' = ON, and (c) $\mathrm{SW}=\mathrm{SW}^{\prime}=\mathrm{ON}$. 
TABLE 1: Possible output switching states under different operation modes of $\mathrm{dc} / \mathrm{dc}$ voltage boosting part.

\begin{tabular}{lccc}
\hline $\begin{array}{l}\text { Operation modes of dc/dc voltage boosting } \\
\text { part }\end{array}$ & SW= SW'=1 & SW $=0, \mathrm{SW}^{\prime}=1$ & \multicolumn{1}{c}{ SW $=1, \mathrm{SW}^{\prime}=0$} \\
\hline $\begin{array}{l}\text { Possible output switching states of NPC } \\
\text { inverter }\end{array}$ & all the switching states shown in Figure 8 & $\begin{array}{l}\{1,0,0\},\{1,1,0\},\{0,1,0\} \\
\{0,1,1\},\{0,0,1\},\{1,0,1\}\end{array}$ & $\begin{array}{l}\{0,-1,-1\},\{0,0,-1\},\{-1,0,-1\} \\
\{-1,0,0\},\{-1,-1,0\},\{0,-1,0\}\end{array}$ \\
\hline
\end{tabular}

PV1 and the inductor L2 current will flow through DX and SX1 (X = A, B or C) to charge the capacitor C2. Similarly, during the operating mode $\left\{\mathrm{SW}=0\right.$ and $\left.\mathrm{SW}^{\prime}=1\right\}$ shown in Figure 6(b), the inductor L2 is charged by the source PV2 and the inductor L1 current will flow through DX' and SX2' to charge the capacitor C1. Figure 6(c) shows the circuit diagram under $\left\{\mathrm{SW}=1\right.$ and $\left.\mathrm{SW}^{\prime}=1\right\}$, where both inductors are charged by the corresponding PV source. And the capacitor voltages $V_{\mathrm{C} 1}$ and $V_{\mathrm{C} 2}$ can be expressed as

$$
\begin{aligned}
& \frac{V_{P V 1}}{L_{1}} \times k_{1} T=\frac{V_{C 1}}{L_{1}} \times\left(1-k_{1}\right) T \Longrightarrow V_{C 1}=\frac{k_{1} V_{P V 1}}{1-k_{1}} \\
& \frac{V_{P V 2}}{L_{2}} \times k_{2} T=\frac{V_{C 2}}{L_{2}} \times\left(1-k_{2}\right) T \Longrightarrow V_{C 2}=\frac{k_{2} V_{P V 2}}{1-k_{2}}
\end{aligned}
$$

where $k_{1}$ and $k_{2}$ represent the duty ratio of SW and $\mathrm{SW}$, respectively; $V_{\mathrm{PVx}}$ refers to the voltage of $\mathrm{PVx}(\mathrm{x}=1$, 2). Therefore, the upper dc-link voltage $V_{\text {up }}$, the lower dclink voltage $V_{\mathrm{dn}}$, and the whole dc-link voltage $V_{\mathrm{dc} \text {-link }}$ are calculated as

$$
\begin{aligned}
V_{u p} & =V_{C 2}+V_{P V 2}, \\
V_{d n} & =V_{C 1}+V_{P V 1} \\
V_{d c \text {-link }} & =V_{u p}+V_{d n}=\frac{V_{P V 1}}{1-k_{1}}+\frac{V_{P V 2}}{1-k_{2}}
\end{aligned}
$$

The dc capacitors together with the PV sources generate the whole dc-link. Compared to the two-stage NPC inverter, the proposed inverter exhibits lower voltage rating of dclink capacitors as well as lower voltage rating of front-end switches.

Further, if assuming $k_{1}=k_{2}=k$ and $V_{\mathrm{PV} 1}=V_{\mathrm{PV} 2}=V_{\mathrm{PV}}$, the voltage boosting ratio can be expressed as

$$
B F=\frac{V_{d c-l i n k}}{V_{P V}}=\frac{2}{1-k}
$$

The relationship of the boost factor with the duty ratio could be shown as Figure 7 according to (6). And the proposed inverter exhibits higher voltage boosting ratio.

To smoothly modulate the dual-source AE-NPC inverter, this paper adopts the phase disposition (PD) modulation scheme. As shown in Figure 8, the three-phase sinusoidal reference lines $m_{A}, m_{B}$, and $m_{C}$ are compared with two carriers to generate the corresponding switching states. Besides, the switching signals of SW' and SW are induced by two additional linear modulation references $V_{U}$ and $V_{L}$, respectively.

Table 1 shows the possible output vectors under different operation modes of voltage boosting part. Take the operation

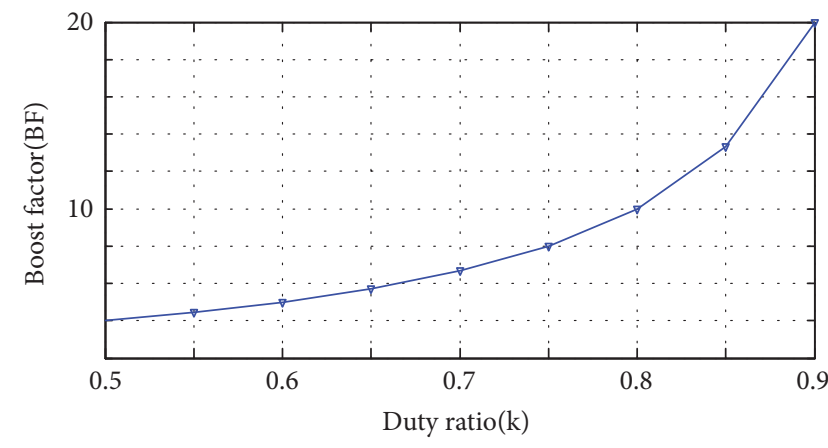

Figure 7: Variation of boost factor (BF) with duty ratio(k).

mode $\left\{\mathrm{SW}=0\right.$ and $\left.\mathrm{SW}^{\prime}=1\right\}$, for example, the NPC inverter can still output the switching states of $\{1,0,0\},\{1,1,0\},\{0,1,0\}$, $\{0,1,1\},\{0,0,1\}$, and $\{1,0,1\}$ shown in Figure 9. Since C2 and PV2 are connected in series to form the upper dc-link voltage and thus can power the rear-end NPC circuit. Similarly, during the operation mode $\left\{\mathrm{SW}=1\right.$ and $\left.\mathrm{SW}^{\prime}=0\right\}$, the NPC inverter can output the switching states $\{0,-1,-1\},\{0,0,-1\},\{-1,0,-1\},\{-$ $1,0,0\},\{-1,-1,0\}$, and $\{0,-1,0\}$. And during the operation mode $\left\{\mathrm{SW}=1\right.$ and $\left.\mathrm{SW}^{\prime}=0\right\}, \mathrm{PV} 1, \mathrm{PV} 2, \mathrm{C} 1$, and $\mathrm{C} 2$ are connected in series to form the whole dc-link voltage. In this mode, the NPC inverter can freely output all the three-level switching states shown in Figure 9.

\section{Control Strategy of Dual-Source AE-NPC Inverter with the Front-End PV Sources}

The main control destination of the dual-source AE-NPC is to implement the MPP operation of both PV sources and keep the output waveform quality. Figure 10 shows the control block of the overall power generation system. And the two MPPT control blocks induce the modulation signals of the two switches SW and SW', respectively. The calculated total input active power is transferred into the output current reference to accurately regulate the output current utilizing the current feedback control. Besides, to balance the upper and lower dc-link voltages, the capacitor voltages $V_{\mathrm{C} 1}, V_{\mathrm{C} 2}$ are controlled individually by modifying the switching states of NPC inverter. The proposed control strategy will be illustrated in the following text.

4.1. Maximum Power Point Control. The perturb and observe MPPT algorithm is assumed to maintain the MPP operation of both PV sources. The PI controller shown in (7) is adopted to precisely track the voltage reference generated by MPPT algorithm. As illustrated in Figure 10, the output of 


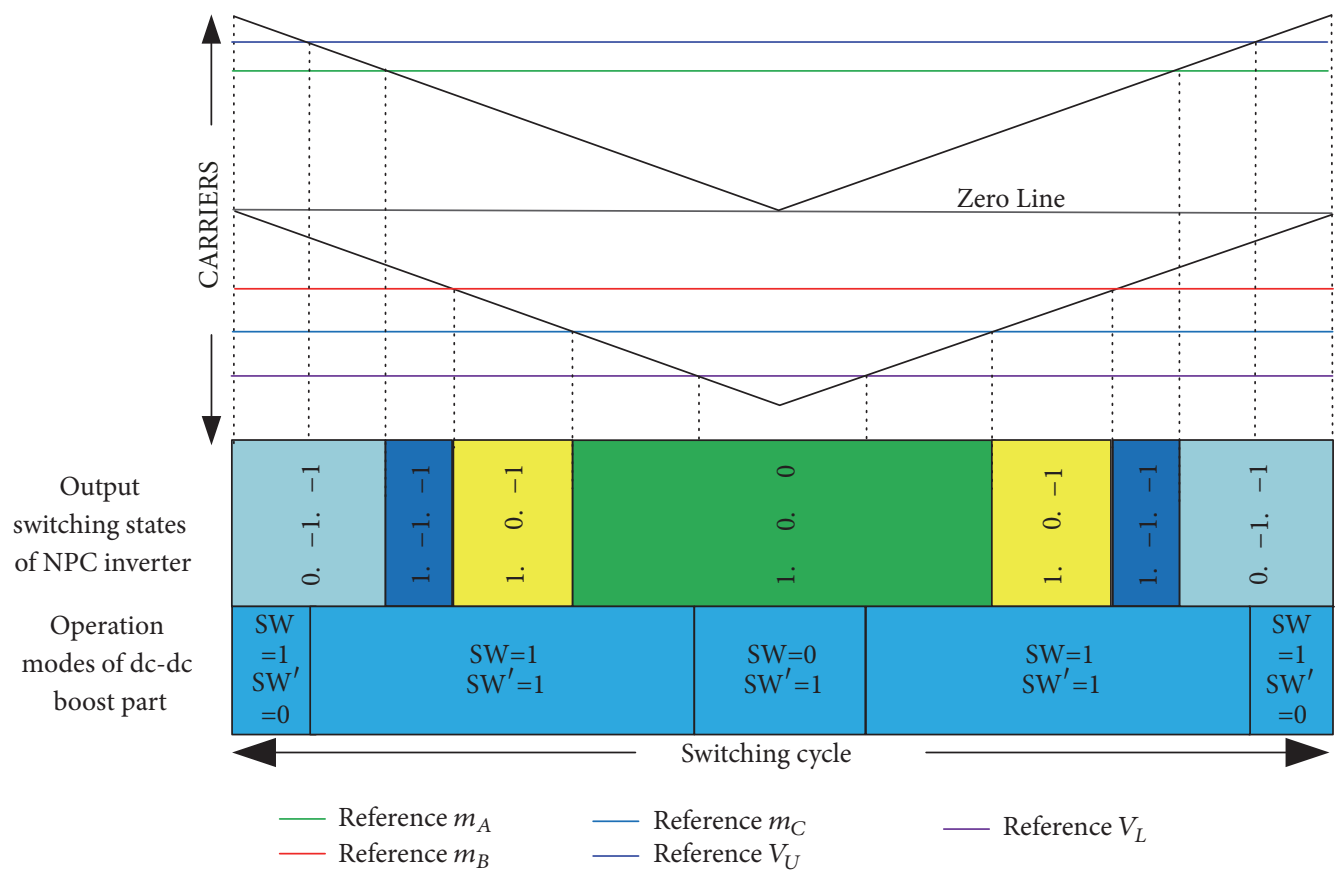

FIGURE 8: Illustration of PD modulation for dual-source AE-NPC inverter.

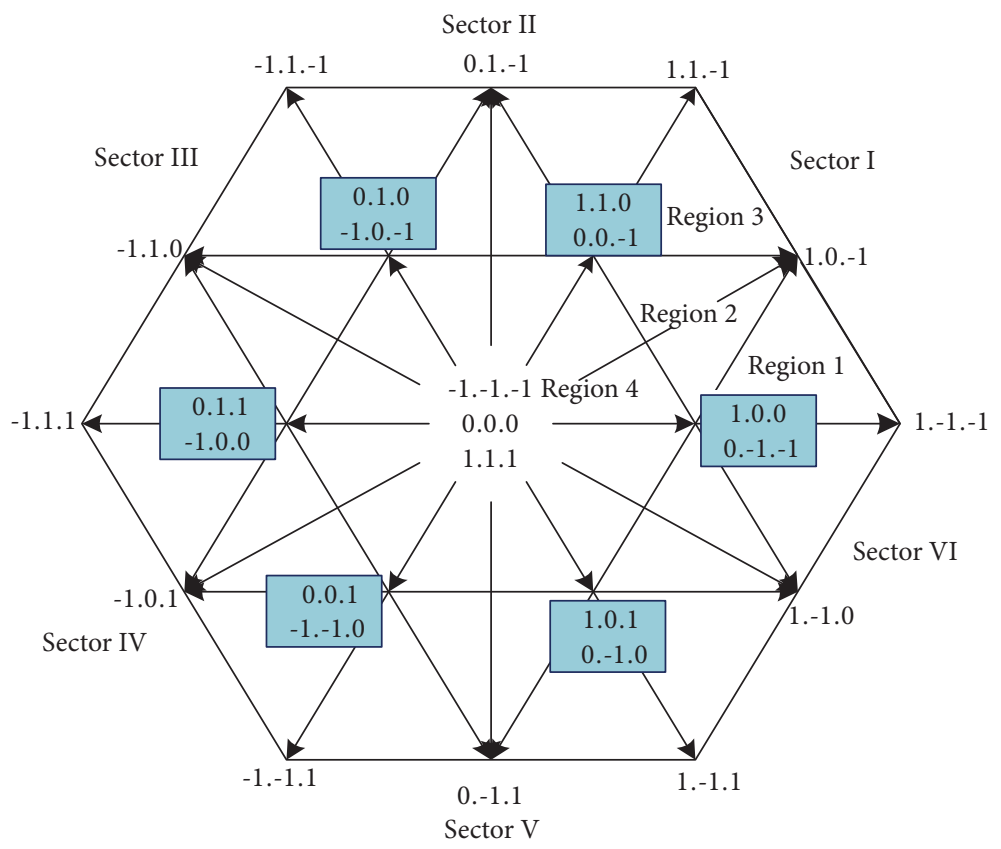

FIGURE 9: Space vector diagram of three-level inverter.

PI controller will be compared with the triangular carrier to generate the modulation signals for SW and SW', respectively.

$$
G_{P I}(s)=k_{p_{-} p i}+k_{i_{-} p i} \frac{1}{s}
$$

where $k_{p_{-} p i}$ is the proportional gain and $k_{i_{-} p i}$ refers to the integral gain.
4.2. Closed-Loop Output Current Control. The ideal current reference is derived as (8), which assumes the unity power factor condition:

$$
I_{g}^{*}=\frac{2\left(P_{P V 1}+P_{P V 2}\right)}{3 V_{g}}
$$

where $I^{*}$ refers to the ideal current reference and $P_{P V x}$ refers to the output active power of $P V x(x=1$ or 2$)$. 


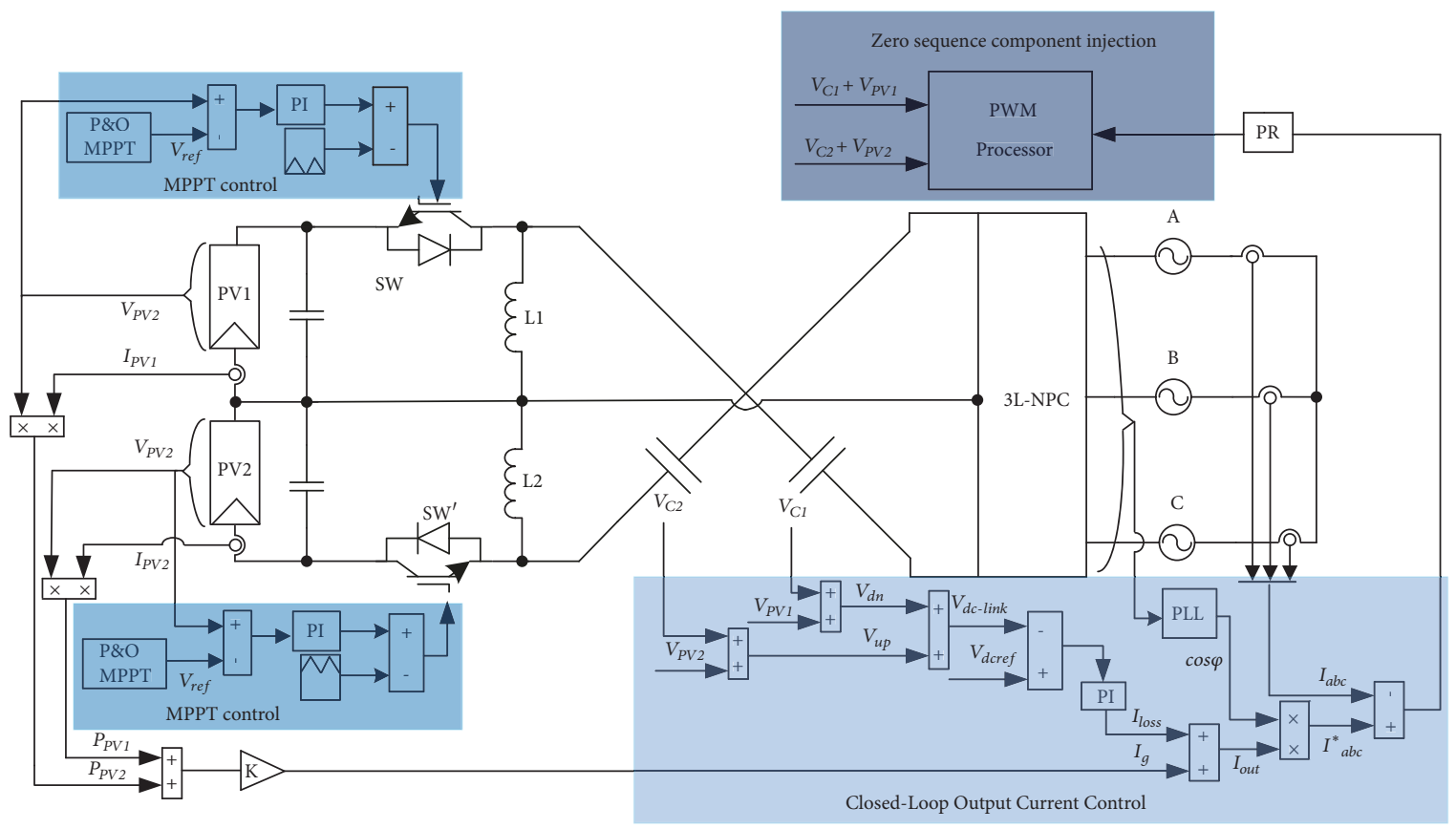

FIGURE 10: Overall control diagram of dual-source AE-NPC inverter for grid-tied PV application.

Moreover, due to the power losses in the circuit, a current reference compensation $I^{*}$ loss generated by the dc-link PI controller should be added to the ideal current reference $I^{*}{ }_{g}$, as shown in Figure 10. The dc-link PI controller is identical to (7). Doing so, the overall dc-link voltage $\left(V_{\mathrm{C} 1}+V_{\mathrm{C} 2}+V_{\mathrm{PV} 1}+\right.$ $V_{\mathrm{PV} 2}$ ) can be regulated as a constant value.

The PR controller expressed in (9) is utilized to precisely track the current reference $\left(I^{*}{ }_{\mathrm{g}}+{I^{*}}_{\text {loss }}\right)$ without steady state error.

$$
G_{P R}(s)=k_{p_{-} p r}+k_{r_{-} p r} \frac{s}{s^{2}+\omega_{0}^{2}}
$$

where $k_{p_{-} p r}$ and $k_{r_{-} p r}$ are the control gains and $\omega_{0}$ is the resonant frequency.

4.3. DC-Link Voltage Balancing Control Method. The PV currents in MPP condition will be different when mismatch appears between the two input PV sources. Consequently, the charging current of $\mathrm{dc}$-link capacitors would be different under the MPP operation, which in turn produces the unbalanced upper and lower dc-link voltages if still utilizing the traditional PD modulation scheme as stated in Section III. The averaged upper and lower dc-link voltages, $V_{\text {up_ave }}$ and $V_{\text {dn_ave }}$, can be expressed as (10) when utilizing no dc-link voltage balancing control scheme:

$$
\begin{aligned}
& V_{\text {up」ave }}=\frac{P_{P V 2} V_{d c-l i n k}}{P_{P V 1}+P_{P V 2}}, \\
& V_{\text {dn_ave }}=\frac{P_{P V 1} V_{d c-l i n k}}{P_{P V 1}+P_{P V 2}}
\end{aligned}
$$

The unbalanced dc-link voltage would induce low-order harmonics and may damage the switches and capacitors because of the overvoltage condition [25]. And the dc-link balance control is the main issue of the NPC converter. Therefore, the possible solution is either to balance the input power, maintaining $P_{\mathrm{PV} 1}=P_{\mathrm{PV} 2}$, which is not desirable since the PV sources will deviate from their MPP operation, or to regulate the discharging currents of dc-link capacitors. The discharging current can be modified by controlling the duration of the inner vectors presented in Figure 9 [26]. For example, two equivalent null states $(0,-1,-1)$ and $(1,0,0)$ per switching sequence in Figure 10 could output the same line-to-line voltage but the opposite neutral current direction. Therefore, adjusting the duration of equivalent null states can change the discharging current of dc-link capacitors and therefore balance the dc-link voltages [26-32]. Based on the duration modification of the equivalent null states, the threephase NPC converter with dual PV arrays can simultaneously realize the dc-link balance and MPP operation under different irradiation [32].

In order to balance dc-link voltages and maintain MPP operations, this paper adopts the zero-sequence component injection method to change the discharging duration of the dc-link capacitors. The illustration of the modified PD modulation strategy with zero-sequence component injection is shown in Figure 11, where the previous reference lines are added by the zero-sequence components $m_{o}$ to achieve dclink balance, that is, $m_{x o}=m_{x}+m_{o}(\mathrm{x}=\mathrm{A}, \mathrm{B}$ or $\mathrm{C})$. And the positive zero-sequence component is injected to increase the duration of state $(1,0,0)$ and to decrease the duration of state $(0,-1,-1)$. Doing so, the upper dc-link voltage decreases; meanwhile it will not induce the low-order harmonic distortion to grid-side current. 


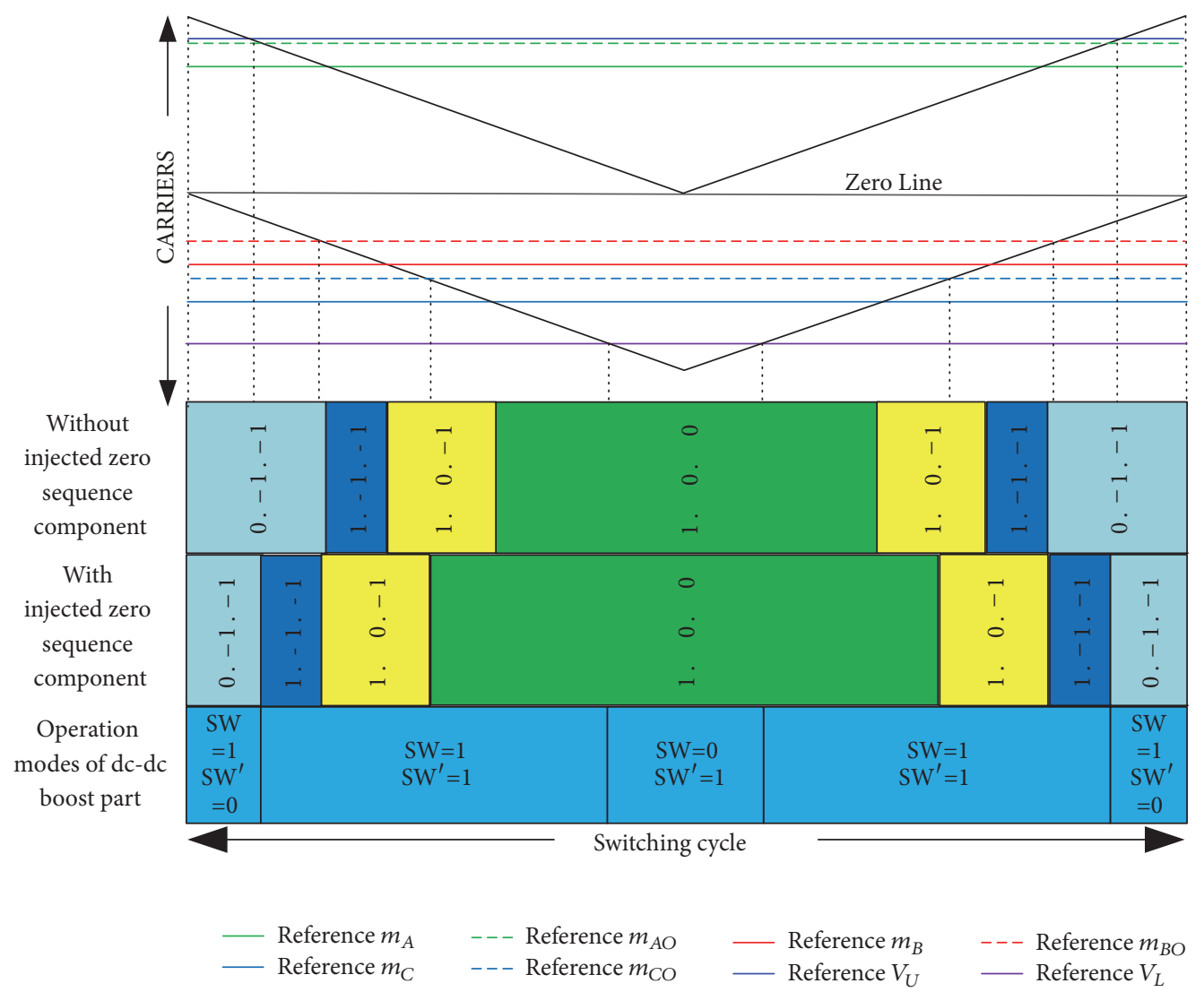

FIGURE 11: Illustration of the modified PD modulation strategy with zero-sequence component injection.

Under the zero-sequence voltage injection, the neutral current $I_{0}$ can be expressed as [26]

$$
\begin{aligned}
I_{0}= & -\left|m_{A O}\right| \cdot I_{g} \cos (\omega \mathrm{t})-\left|m_{B O}\right| \cdot I_{g} \cos \left(\omega t-\frac{2 \pi}{3}\right) \\
& -\left|m_{C O}\right| \cdot I_{g} \cos \left(\omega t+\frac{2 \pi}{3}\right)
\end{aligned}
$$

where $I_{\mathrm{g}}$ refers to the amplitude of output ac current and the zero-sequence component $m_{\mathrm{o}}$ can be written as

$$
m_{0}= \begin{cases}M-\max \left(m_{A}, m_{B}, m_{C}\right) & V_{u p}>V_{d n} \\ -M-\min \left(m_{A}, m_{B}, m_{C}\right) & V_{u p}<V_{d n}\end{cases}
$$

where $M$ refers to the modulation index. Figure 12 illustrates the modulation reference with the zero-sequence component. In addition, the averaged neutral current $I_{0 \text { ave }}$ can be derived as

$$
I_{0 \_ \text {ave }}=\frac{1}{2 \pi} \int I_{0}(w t) d(w t)
$$

According to (11)-(13), the discharging currents of dclink capacitors will be regulated unequally by controlling the averaged neutral current. Moreover, the dc-link voltage can

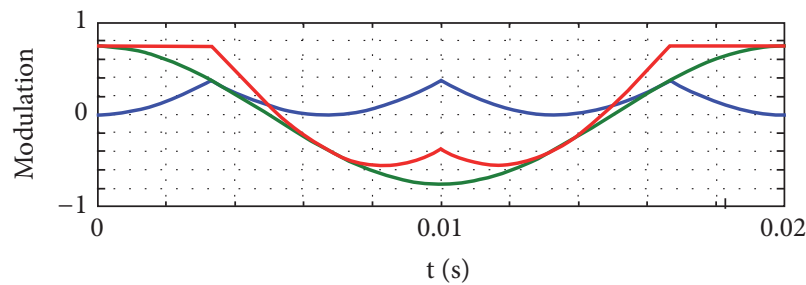

_the modulation signals with third harmonic components
the modulation signals
the injected third harmonic components

FIgUrE 12: The ideal modulation references of the AE-NPC converter.

be balanced when the averaged output currents of the dc-link capacitors satisfy the following equation:

$$
\begin{aligned}
& \left.\begin{array}{l}
\frac{V_{d c-l i n k} I_{u p_{a v e}}}{2}=P_{P V 2} \\
\frac{V_{d c-l i n k} I_{d n_{\text {ave }}}}{2}=P_{P V 1}
\end{array}\right\} \Longrightarrow I_{\text {upave }}-I_{d n \_a v e} \\
& =\frac{2\left(P_{P V 2}-P_{P V 1}\right)}{V_{d c-l i n k}}=-I_{0 \text { ave }}
\end{aligned}
$$

where $I_{\text {up ave }}$ and $I_{\text {dn_ave }}$ refer to the averaged discharging currents of dc-link capacitors $\mathrm{C} 2$ and $\mathrm{C} 1$, respectively. The 
zero-sequence component injection can realize the dc-link balance and MPP operation. However, such regulation has a limitation since the range of controlled averaged neutral current is limited. According to (12)-(13), the range of the averaged neutral current $I_{0 \_a v e}$ can be derived as

$$
-0.33 M I_{g} \leq I_{0 \_ \text {ave }} \leq 0.33 M I_{g}
$$

Further, according to (14) and (15), the dc-link voltage can be balanced under the following condition:

$$
0.64 \leq \frac{P_{P V 1}}{P_{P V 2}} \leq 1.56
$$

\section{Efficiency Comparison}

Compared to the two-level inverter, the NPC inverter exhibits higher efficiency when both switching frequency are greater than $8 \mathrm{kHz}$ [33]. Since the switching frequency in the PV application with rated power $<30 \mathrm{~kW}$ is $10 \mathrm{kHz}$ or more, the two-stage three-level NPC inverter will be more efficient than the two-level converter. On the other hand, along with the mature of $1500 \mathrm{~V}$ PV panel technology, the PV system can be integrated into a high voltage grid (e.g., 690V grid) to reduce losses. In this case, the NPC inverter could be deemed as a competitive candidate in practice. Therefore, the efficiency comparison in this paper will be focused on the two-stage NPC inverter and the proposed dual-source AENPC inverter.

Before analyzing the switching losses, a fair basis for comparison is drawn by tuning the inverters to produce the same input-to-output voltage gain. The duty ratios of frontend switches SW and SW' in dual-source AE-NPC inverter and two-stage NPC inverter can be derived as

$$
\frac{M_{B}}{2\left(1-k_{B}\right)}=\frac{M_{S}}{1-k_{S}} ; \quad 0.5 \leq k_{S}, \quad k_{B} \leq 1
$$

where the subscripts " $B$ " and " $S$ " indicate the variable of two-stage NPC inverter and the proposed single-stage NPC inverter, respectively. Specifically, $M_{B}$ and $k_{B}$ represent the ac modulation index and dc-end transistor duty ratio in two-stage NPC inverter, while $M_{S}$ and $k_{S}$ represent the ac modulation index and dc-end transistor duty ratio in the proposed single-stage NPC inverter. As analyzed above, the modulation index $M_{\mathrm{S}}$ of dual-source AE-NPC inverter should be set to $k_{S}$ to maximize the dc-link voltage utilization, while the modulation index $M_{\mathrm{B}}$ of two-stage NPC inverter is independent on $k_{B}$, which can be set to 1 . Then the relationship of dc-link voltages of both inverters can be described as

$$
V_{d c-l i n k, B}=k_{S} V_{d c-l i n k, S}
$$

The dual-source AE-NPC inverter suffers a higher dclink voltage stress and more switching losses in the rearend NPC circuit. However, the blocking voltage of the frontend switches SW and SW' in dual-source AE-NPC inverter is lower than that of the switches and diodes in two-stage NPC inverter, thus the dual-source AE-NPC inverter suffers lower switching losses in the front-end circuit. Since the conduction currents of both inverters keep equal at any instant, conduction dissipation of the rear-end NPC circuitry will not be discussed in this paper.

The switching and conduction dissipations of the IGBTs used in both topologies can be derived as $[34,35]$

$$
\begin{aligned}
P_{\text {switch }} & =\frac{1}{2} V_{\mathrm{OFF}} I_{\mathrm{ON}} t_{\text {tr }} f_{S W} \\
P_{\text {cond }} & =V_{\mathrm{CE}} I_{\mathrm{ON}-\text { ave }}
\end{aligned}
$$

where $P_{\text {switch }}$ refers to the total switching dissipation of single-stage or two-stage converter, $V_{C E}$ refers to collectoremitter saturation voltage, and $V_{\text {OFF }}$ refers to the turn-on or turn-off voltage of switches. $I_{\mathrm{ON}}$ represents the conducting current of the switches, $t_{t r}$ represents the sum of turn-on and turn-off transient duration of switches, and $f_{S W}$ refers to switching frequency. The switching dissipation of both inverters can be derived as follows.

Dual-Source AE-NPC Inverter

$$
\begin{aligned}
& P_{\text {switch_dc(S) }}=\frac{1}{2} V_{d c-l i n k, S} I_{L, S} t_{t r} f_{S W} \\
& P_{\text {switch_ac }(S)}=\frac{3}{\pi} V_{d c-l i n k, S} I_{g} t_{t r} f_{S W} \\
& P_{\text {switch }(S)}=P_{\text {switch_dc(S) }}+P_{\text {switch_dc(S) }} \\
& =t_{t r} f_{S W}\left(P_{P V 1}+P_{P V 2}\right)\left(V_{g}+V_{P V}\right)\left(\frac{4}{\pi V_{g}}+\frac{1}{2 V_{P V}}\right)
\end{aligned}
$$

Two-Stage NPC Inverter

$$
\begin{aligned}
P_{\text {switch_dc }(B)} & =V_{d c-l i n k, B} I_{L, B} t_{t r} f_{S W} \\
P_{\text {switch_ac }(B)} & =\frac{3}{\pi} V_{d c-l i n k, B} I_{g} t_{t r} f_{S W} \\
P_{\text {switch }(B)} & =P_{\text {switch_dc(B) }}+P_{\text {switch_ac }(B)} \\
& =t_{t r} f_{S W}\left(P_{P V 1}+P_{P V 2}\right)\left(\frac{4}{\pi}+\frac{V_{g}}{V_{P V}}\right)
\end{aligned}
$$

where $I_{L, X}(\mathrm{X}=\mathrm{B}$ or $\mathrm{S})$ refers to input inductor current and $P_{\text {switch } \_c(X)}$ and $P_{\text {switch } \_c(X)}(\mathrm{X}=\mathrm{B}$ or $\mathrm{S})$ represent the $\mathrm{dc}$ and ac side switching dissipation. It is calculated from (20)(21) that the proposed single-stage PV converter suffers lower switching dissipation when the boosting ratio $\left(V_{g} / V_{P V}\right)$ is greater than 2.17. Furthermore, when considering the conduction losses, the forward voltage drops of the diodes and switches are assumed to be equal; therefore the conduction dissipation of the front-end circuit can be calculated as

$$
\begin{aligned}
P_{\text {cond }(S)} & =2 \times V_{C E} I_{L, S}+2 \times 2 V_{C E}\left(1-k_{S}\right) I_{L, S} \\
& =\frac{V_{C E}}{V_{P V}}\left(P_{P V 1}+P_{P V 2}\right)\left(1+\frac{2 V_{P V}}{V_{P V}+V_{g}}\right)
\end{aligned}
$$



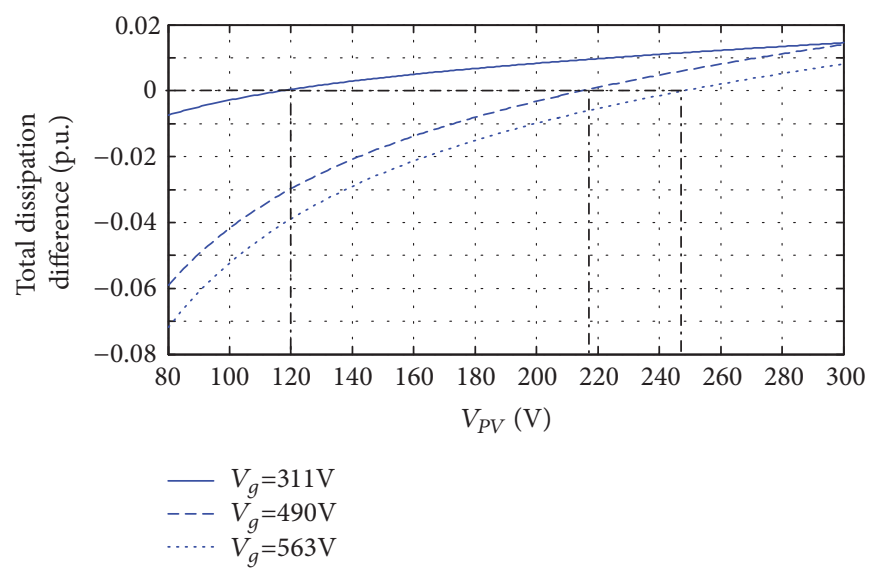

(a)

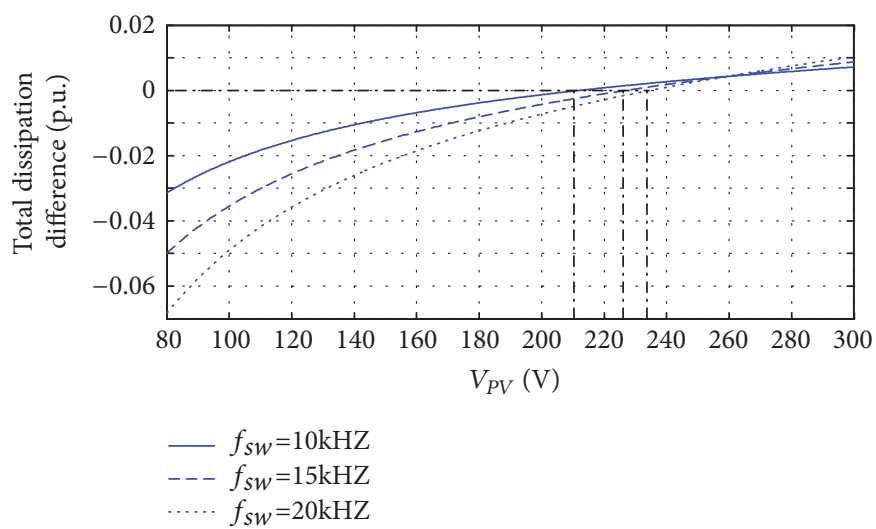

(b)

FIGURE 13: Dissipation comparison under (a) different ac output voltages and (b) different switching frequencies.

$$
\begin{aligned}
P_{\text {cond }(B)} & =2 \times V_{C E} k_{B} I_{L, B}+2 \times V_{C E}\left(1-k_{B}\right) I_{L, B} \\
& =\frac{V_{C E}}{V_{P V}}\left(P_{P V 1}+P_{P V 2}\right)
\end{aligned}
$$

where $2 \times V_{C E} I_{L, S}$ and $2 \times V_{C E} k_{B} I_{L, B}$ represent the conduction dissipations during the switch $\mathrm{ON}$ period, while $2 \times 2 V_{C E}\left(1-k_{S}\right) I_{L, S}$ and $2 \times V_{C E}\left(1-k_{B}\right) I_{L, B}$ represent the conduction dissipations during the switch OFF period. According to (22), the dual-source AE-NPC inverter always suffers a higher conduction loss than the two-stage NPC inverter. However, the conduction loss can be reduced by using the devices with a lower collector-emitter saturation voltage since the blocking voltages of SW and SW' are only half of the dc-link voltage, unlike that of the traditional two-stage NPC inverter. And the total dissipation difference between both converters can be derived from (20)-(22), which is written below:

$$
\begin{gathered}
\Delta P_{d i s}=\left[t_{t r} f_{S W}\left(\frac{4 V_{P V}}{\pi V_{g}}-\frac{V_{g}}{2 V_{P V}}+\frac{1}{2}\right)+\frac{2 V_{C E}}{V_{g}+V_{P V}}\right] \\
\cdot\left(P_{P V 1}+P_{P V 2}\right)
\end{gathered}
$$

where $\Delta P_{\text {dis }}$ represents the total dissipation difference. It is noted from (23) that the dissipation comparison between both converters is related to the parameters of switching frequency $f_{S W}$, input PV voltage $V_{P V}$, grid voltage $V_{g}$, and collector-emitter saturation voltage $V_{C E}$. In this case, the theoretical calculation assumes the IGBT of FF150R17KE4 produced by Infineon with $V_{C E}, t_{t r}$, and $f_{S W}$ to be $1.75 \mathrm{~V}$, $1300 \mathrm{~ns}$, and $20 \mathrm{kHz}$, respectively. The calculation results are drawn in Figure 13. When PV voltage is below the threshold voltages shown in Figure 13(a), the dual-source AE-NPC inverter exhibits lower dissipation than the two-stage inverter $\left(\Delta P_{d i s}<0\right)$. For the condition $V_{g}=311 \mathrm{~V}, 490 \mathrm{~V}$, and $563 \mathrm{~V}$, the threshold voltages equal $120 \mathrm{~V}, 217 \mathrm{~V}$, and $246 \mathrm{~V}$, respectively. Also, the dissipation comparisons under different PV voltages and switching frequencies are presented in Figure 13(b), where $V_{g}$ is equal to $563 \mathrm{~V}$.

In general, compared to the two-stage NPC inverter, the proposed dual-source AE-NPC inverter saves two diodes and exhibits lower voltage rating for dc-link capacitors and frontend switches. Moreover, the proposed inverter exhibits higher efficiency under high voltage boosting ratio conditions.

\section{Simulation and Experimental Verifications}

The proposed AE-NPC inverter is built by MATLAB/ SIMULINK. And Table 2 shows the parameters of the AENPC circuit and two PV sources. In addition, the PV array 


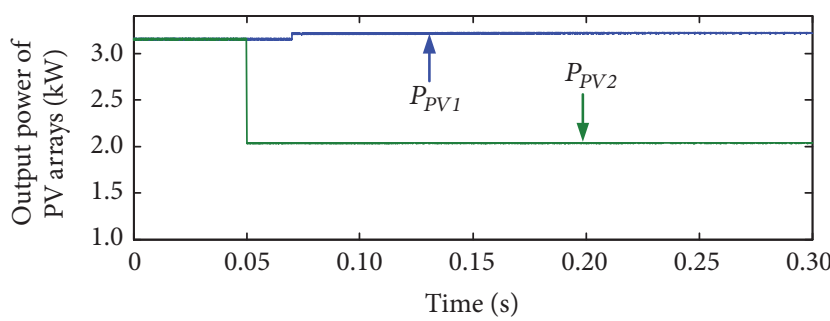

(a)

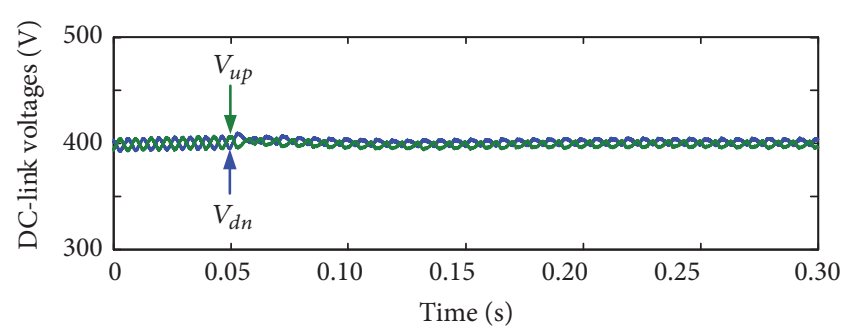

(c)

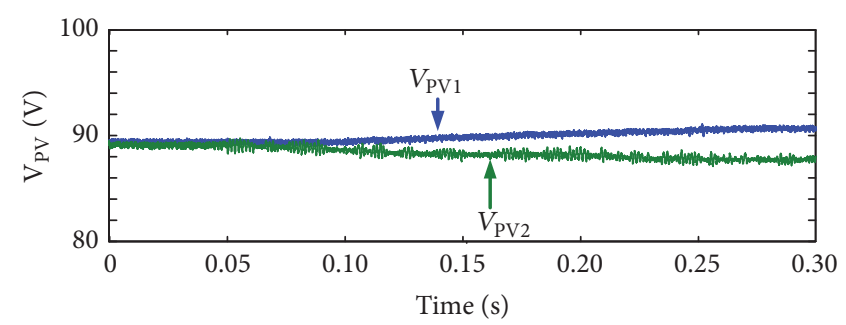

(b)

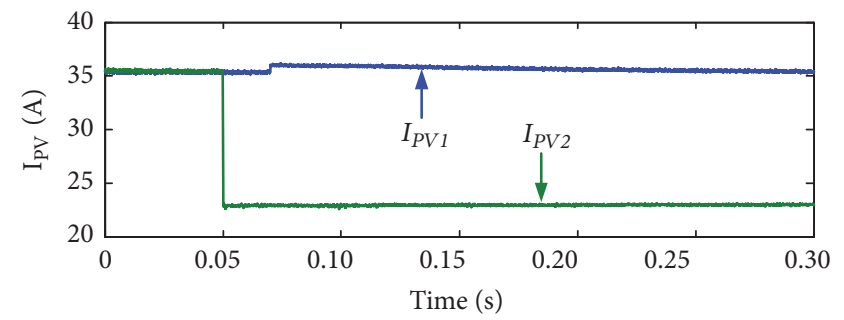

(d)

FIGURE 14: Simulated results of (a) output PV power, (b) PV voltages, (c) upper/lower dc-link voltages, and (d) PV currents.

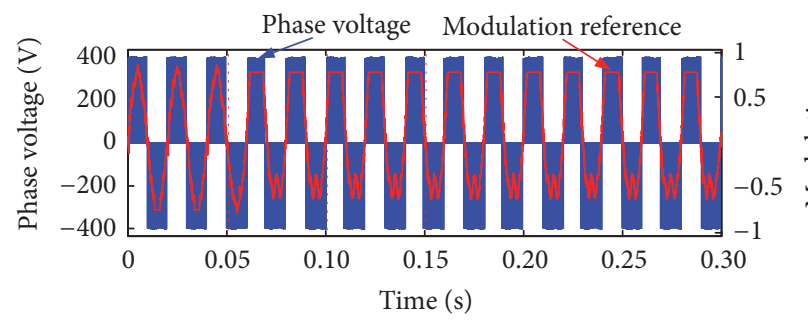

(a)

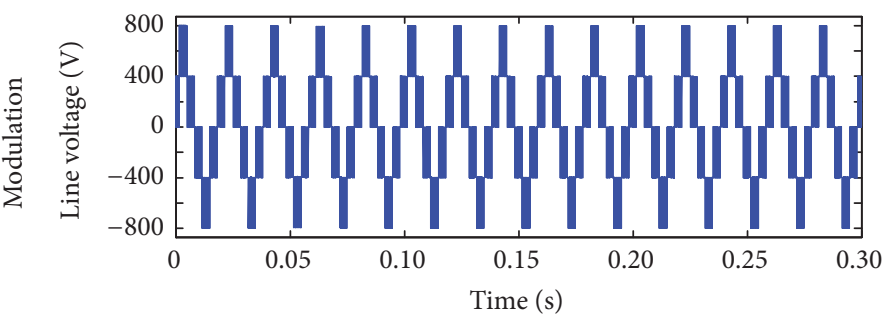

(b)

FIGURE 15: Output waveform of (a) switching phase voltage and its modulation reference and (b) switching line voltage.

TABLE 2: Simulation parameters.

\begin{tabular}{lccc}
\hline Parameter & value & Parameter & value \\
\hline $\begin{array}{l}\text { dc-side inductor }(\mathrm{L} 1, \mathrm{~L} 2) \\
\text { dc-link capacitor }(\mathrm{Cl},\end{array}$ & $1 \mathrm{mH}$ & $\begin{array}{c}\text { ac-side filter inductor } \\
\text { grid phase voltage } \\
\text { amplitude }\left(V_{g}\right)\end{array}$ & $311 \mathrm{mH}$ \\
$\begin{array}{l}\text { C2 }) \\
\begin{array}{l}\text { overall dc-link voltage } \\
\left(V_{C 1}+V_{C 2}+V_{P V 1}+V_{P V 2}\right)\end{array}\end{array}$ & $800 \mathrm{~V}$ & $\begin{array}{c}\text { carrier frequency } \\
\left(f_{S W}\right)\end{array}$ & $10 \mathrm{kHZ}$ \\
$\begin{array}{l}\text { PV array short-circuit } \\
\text { current }\left(1000 \mathrm{~W} / \mathrm{m}^{2}\right)\end{array}$ & $38 \mathrm{~A}$ & $\begin{array}{c}\mathrm{PV} \text { array open circuit } \\
\text { voltage }\left(0^{\circ} \mathrm{C}\right)\end{array}$ & $109 \mathrm{~V}$ \\
\hline
\end{tabular}

for the transformer-less PV is connected to the grid without galvanic isolation and the voltage fluctuation between the PV array and the ground would generate leakage current. The leakage current could be eliminated by effectively reducing the fluctuation of the common-mode voltage (CMV). In general, there are two main methods to eliminate the leakage current. Firstly, the variation of the CMV could be reduced by applying the specific vectors utilizing the Space Vector Modulation strategy [36]. Secondly, the common-mode component could be attenuated by the passive filter network presented in [37]. And the passive filter was utilized in this paper to eliminate the leakage current.
Figure 14 shows the simulated PV voltage, PV power, upper/lower dc-link voltages, and PV currents under temperature and irradiation variations, the irradiation of PV1 varies from $1000 \mathrm{~W} / \mathrm{m}^{2}$ to $650 \mathrm{~W} / \mathrm{m}^{2}$ at $0.05 \mathrm{~s}$, and the temperature of PV2 decreases from $15^{\circ} \mathrm{C}$ to $10^{\circ} \mathrm{C}$ at $0.07 \mathrm{~s}$. Therefore, the output power of PV1 is decreased to about $2000 \mathrm{~W}$ at $0.05 \mathrm{~s}$ and PV2 output power increases $70 \mathrm{~W}$ at $0.07 \mathrm{~s}$ because of temperature variation. Moreover, the proposed control strategy can fast track the MPP variation, which is shown in Figure 14(a). Figure 14(b) shows the PV voltages under their corresponding MPPs. Figure 14(c) shows that the dc-link voltage can be balanced, and the proposed method could modify the switching states of NPC circuit to compensate the mismatching of upper and lower PV arrays. And the PV currents under the MPP operation condition are shown in Figure 14(d). Moreover, the PV2 current almost keeps unchanged when the PV2 temperature varies to $10^{\circ} \mathrm{C}$, and the PV1 current has a sharp decline because of the irradiation variation. However, different PV currents would not affect the whole operational effectiveness due to the novel topological circuit.

Further, the voltage and current of NPC inverter are shown in Figures 15 and 16, respectively. Figure 15 shows one switching phase voltage, one switching line voltage, and its 


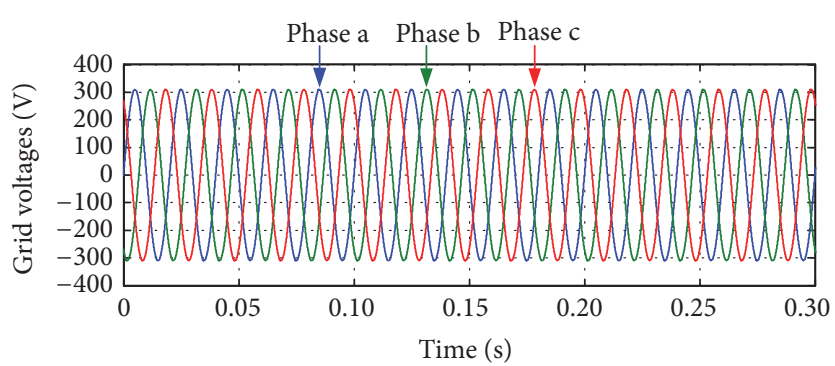

(a)

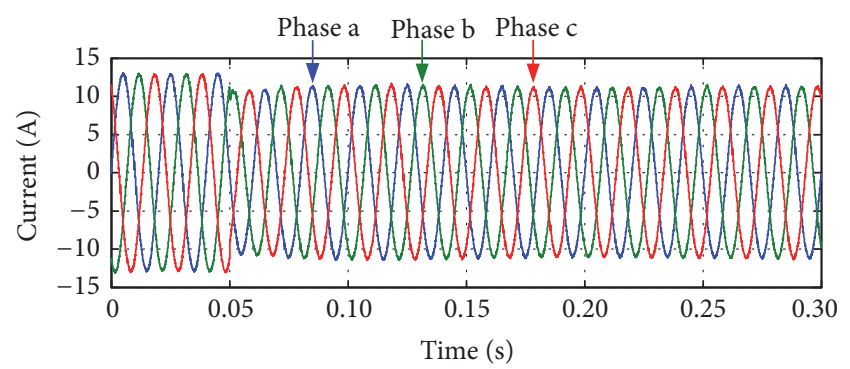

(b)

FIGURE 16: Waveforms of (a) grid voltages and (b) grid currents.

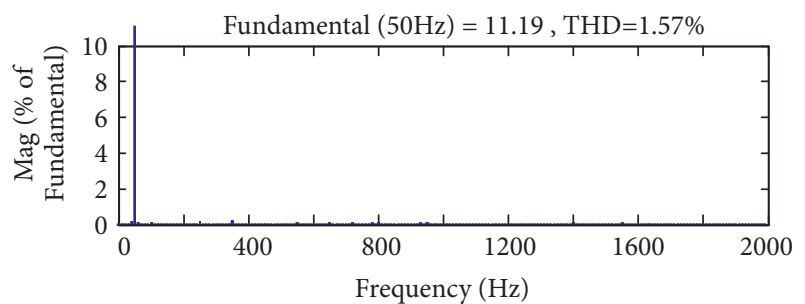

FIgURE 17: FFT analysis of the output AC current.

TABLE 3: Experimental parameters.

\begin{tabular}{lccc}
\hline Parameter & value & Parameter & value \\
\hline $\begin{array}{l}\text { dc-side inductor }(\mathrm{L} 1, \mathrm{~L} 2) \\
\text { fc-link capacitor }(\mathrm{C} 1,\end{array}$ & $1 \mathrm{mH}$ & $\begin{array}{c}\text { filter inductor of ac } \\
\text { side }\end{array}$ & $5 \mathrm{mH}$ \\
$\begin{array}{l}\mathrm{C} 2) \\
\begin{array}{l}\text { overall dc-link voltage } \\
\left(V_{C 1}+V_{C 2}+V_{P V 1}+V_{P V 2}\right)\end{array}\end{array}$ & $460 \mathrm{~V}$ & $\begin{array}{c}\text { grid phase voltage } \\
\left(V_{g}\right)\end{array}$ & $155 \mathrm{~V}$ \\
$\begin{array}{l}\mathrm{PV} \text { array short-circuit frequency } \\
\text { current }\left(1000 \mathrm{~W} / \mathrm{m}^{2}\right)\end{array}$ & $8 \mathrm{~A}$ & $\begin{array}{c}\mathrm{PV} \text { array open circuit } \\
\text { voltage }\left(0^{\circ} \mathrm{C}\right)\end{array}$ & $58.3 \mathrm{VHZ}$ \\
\hline
\end{tabular}

modulation signal. As shown in Figure 15, after the zerosequence component injection at $0.05 \mathrm{~s}$, the modulation signal and the switching characteristics of phase voltage will be changed. However, such changes will not lead to the normalized volt-sec average change and the three-phase output currents are still purely sinusoidal, as shown in Figure 16. Moreover, the FFT analysis of the grid current is shown in Figure 17 and the total harmonic distortion (THD) of output AC current is $1.57 \%$.

Next, proceeding to the experimental verification, the corresponding experimental parameters are listed in Table 3. Two rooftop installed PV sources were used, whose maximum power points are both $50 \mathrm{~V}$ and 7.4A. The output power of the whole PV arrays is about $700 \mathrm{~W}$, and the amplitude of output ac current is about 3.0A. The picture of experimental prototype is shown in Figure 18. The waveforms of grid voltage and output currents are shown in Figure 19. It is noted that the inverter can output the balanced sinusoidal currents. The harmonic spectrum of phase current is shown in Figure 20. Fortunately, the zero-sequence component injection method

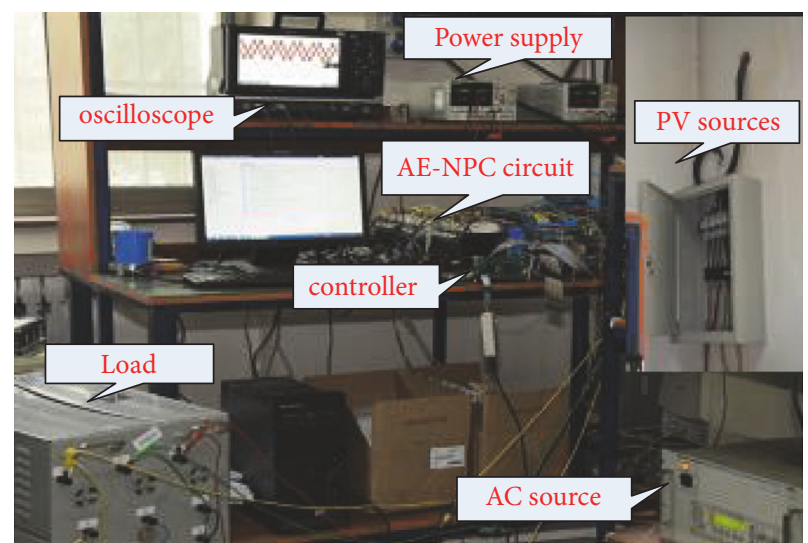

FIgURE 18: The experimental prototype of dual-source AE-NPC inverter.

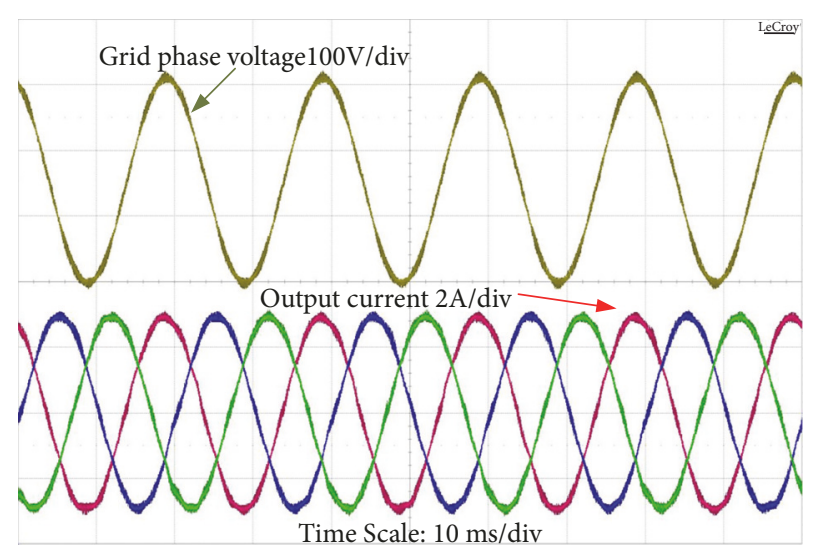

FIGURE 19: Captured grid voltages and output currents.

did not produce the low-order harmonic distortion and the THD of phase current is $2.56 \%$.

The switching phase voltages and phase B current are shown in Figure 21, and Figure 22 presents the switching line voltages and output currents, where the output current is purely sinusoidal.

Figures 23(a) and 23(b) present the experimental waveforms under the situations where the PV voltage references are suddenly changed to examine the dynamic performance 


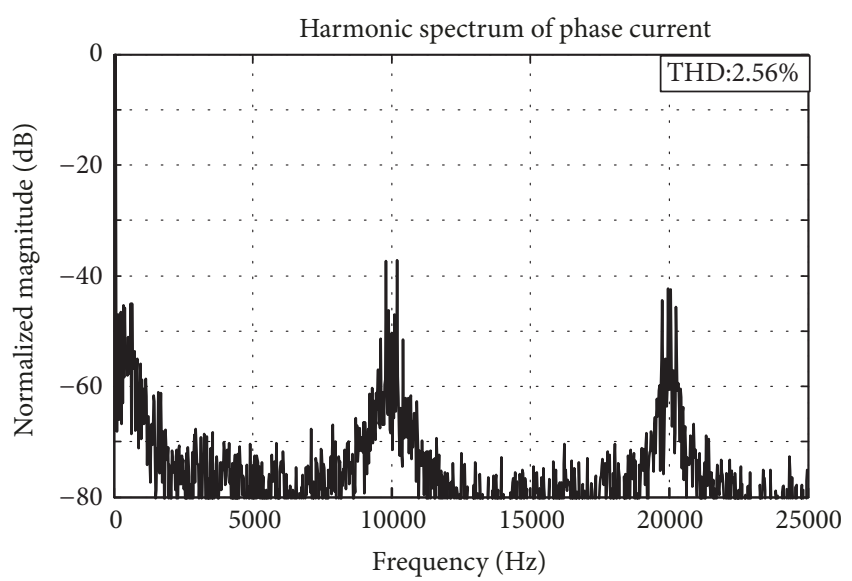

FIgURE 20: Harmonic spectrum of phase current.

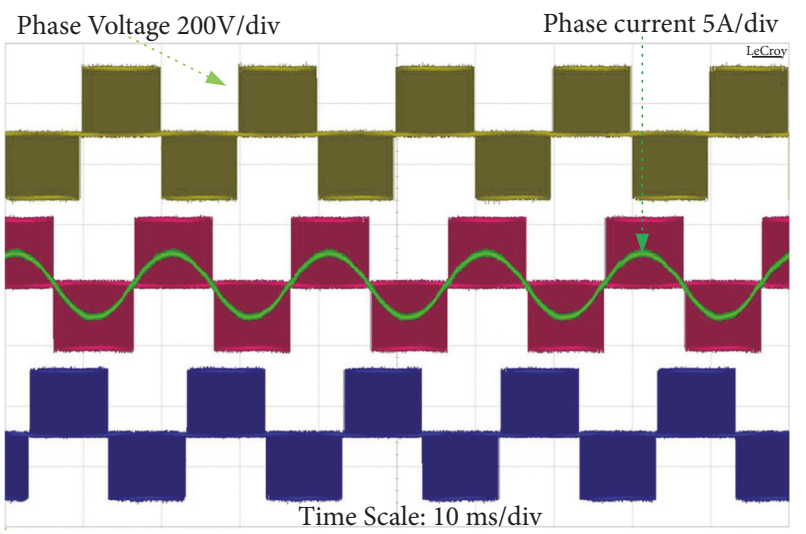

FIGURE 21: Switching phase voltages and phase B current.

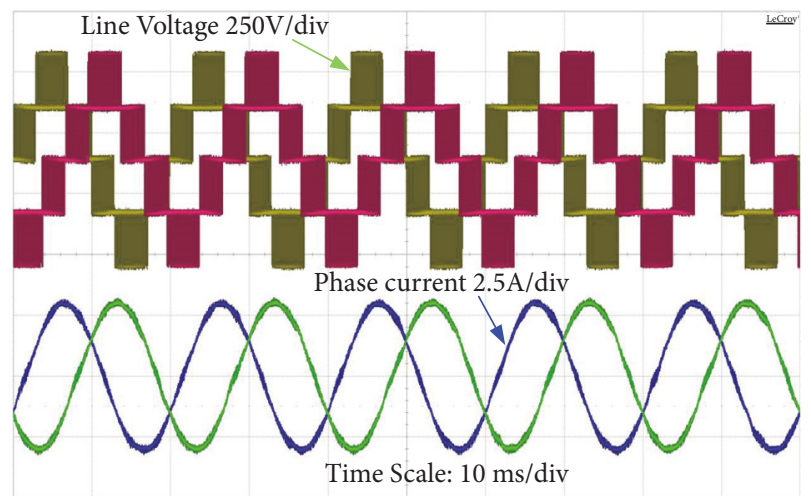

FIGURE 22: Switching line voltages and phase currents.

on PV MPP voltage tracking and dc-link voltage balancing. In Figure 23(a), PV2 voltage reference declines to $35 \mathrm{~V}$ at instant $t_{1}$ and recovers to $50 \mathrm{~V}$ at instant $t_{2}$. Owing to the proposed dc-link balancing control method, the voltage $V_{C 2}$ rises up to $195 \mathrm{~V}$ at instant $t_{1}$, so that the upper and lower dc-link voltages could be regulated symmetrically. Similarly, in Figure 23(b), PV2 voltage reference rises up to $65 \mathrm{~V}$ at

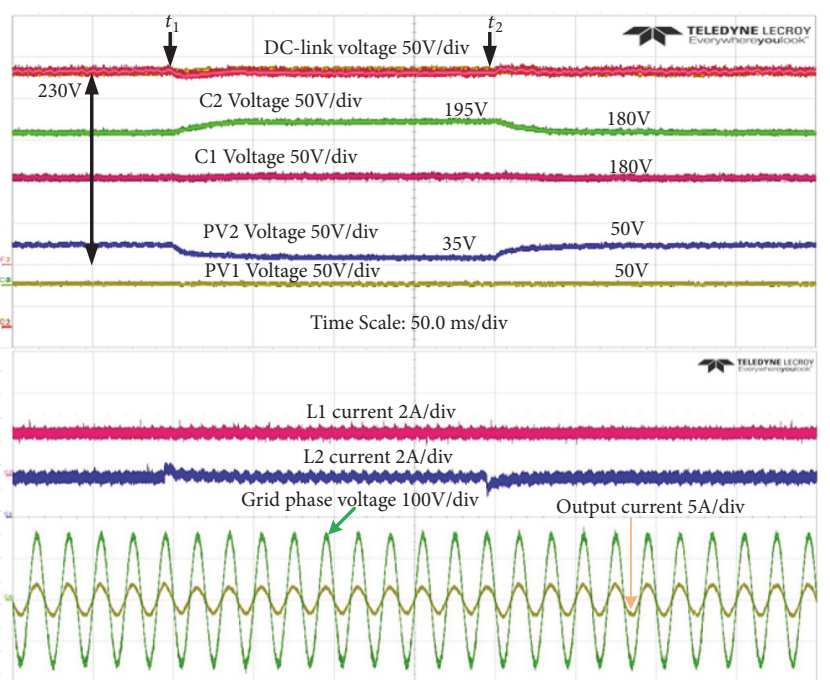

(a)

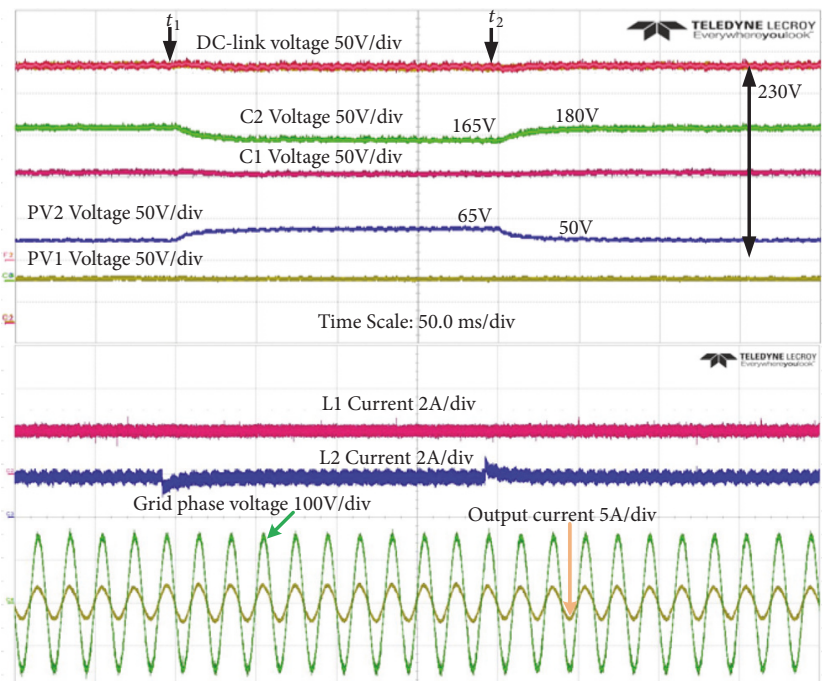

(b)

FIGURE 23: Experimental results of (a) PV2 voltage reference dip and (b) PV2 voltage reference swell.

instant $t_{1}$ and recovers to $50 \mathrm{~V}$ at instant $t_{2}$. The voltage $V_{\mathrm{C} 2}$ declines to $165 \mathrm{~V}$ at instant $t_{1}$ due to the participation of dc-link balancing control method, therefore the upper and lower dc-link voltages are kept balanced. Meanwhile, since the dc-link voltage is well-balanced, the grid current quality is acceptable during both scenarios presented in Figures 23(a) and 23(b).

Besides, the dynamic performance of dual-source AENPC inverter under unsymmetrical irradiation is investigated. Since the irradiation of rooftop installed PV panel cannot be suddenly changed, two programmable dc sources (Chroma 62150H) were used to emulate the PV panels. As shown in Figure 24, one emulated PV current suffers a sudden dip at instant $t_{0}$. The dc-dc part still manages to track the dual PV voltage at $50 \mathrm{~V}$ effectively, while the NPC inverter takes the responsibility to balance the dc-link 


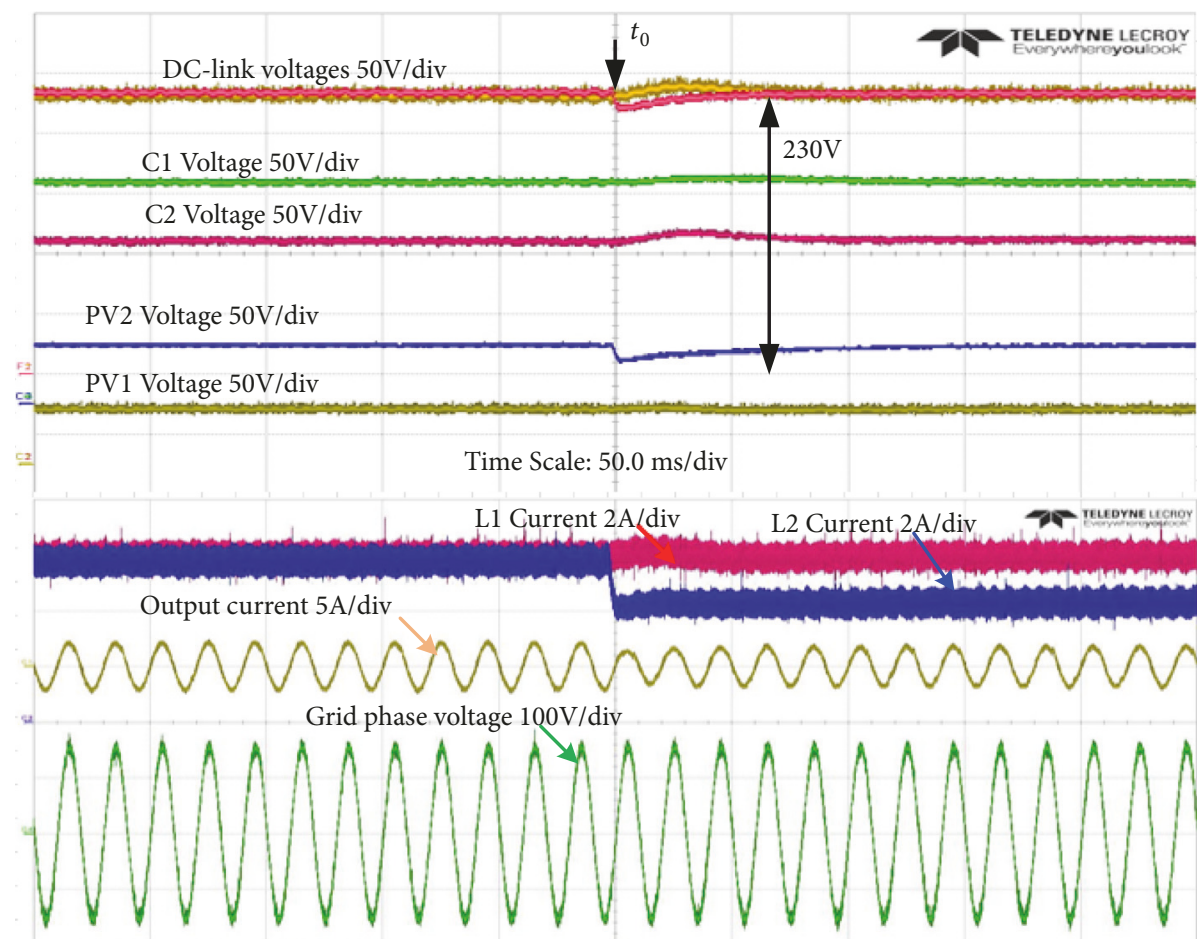

FIGURE 24: Experimental results of irradiation sudden change of PV2 source.

voltage. Consequently, the upper and lower dc-link voltages $\left(V_{C 2}+V_{P V 2}\right)$ and $\left(V_{C 1}+V_{P V 1}\right)$ can be balanced and stabilized in a short interval; also the grid current quality is acceptable under the unbalanced irradiation condition.

\section{Conclusions}

This paper proposes a novel single-stage buck-boost threelevel NPC inverter, which can couple two separate dc sources in front and balance the upper and lower dc-link voltages. The corresponding operational principles are analyzed. When it is applied as the interfacing circuit between PV arrays and power grid, the zero-sequence component injection method can be employed to balance the dc-link voltage whenever the irradiation and temperature between two PV arrays are different. In addition, this paper illustrates the overall control scheme of the proposed converter for gridtied PV application and compares the efficiency performance. MATLAB simulations and experimental results verified the performance of the proposed converter.

\section{Data Availability}

The data used to support the findings of this study are available from the corresponding author upon request.

\section{Conflicts of Interest}

The authors declare that they have no conflicts of interest.

\section{Acknowledgments}

The research and publication of the article are funded by the Project of National Key Research and Development Plan (2017YFB0903300) and the Project of Control and Coordinated Operation of SiC based Power Electronic Transformer (Science and Technology Project of State Grid Jiangsu Electric Power Co., Ltd.).

\section{References}

[1] H. Hamed and M. Mohammad, "An integrated interleaved dual-mode time-sharing inverter for single-phase grid-tied applications," IEEE Transactions on Industrial Electronics, vol. 66, pp. 286-296, 2019.

[2] L. Liu, H. Li, Y. Xue, and W. Liu, "Decoupled active and reactive power control for large-scale grid-connected photovoltaic systems using cascaded modular multilevel converters," IEEE Transactions on Power Electronics, vol. 30, no. 1, pp. 176-187, 2015.

[3] S. Kim, I. J. Won, J. Kim, and K. Lee, "DC-link ripple current reduction method for three-level inverters with optimal switching pattern," IEEE Transactions on Industrial Electronics, vol. 65, no. 12, pp. 9204-9214, 2018.

[4] N. Prabaharan and K. Palanisamy, "Analysis and integration of multilevel inverter configuration with boost converters in a photovoltaic system," Energy Conversion and Management, vol. 128, pp. 327-342, 2016.

[5] P. Guerriero, M. Coppola, F. D. Napoli et al., "Three-phase PV CHB inverter for a distributed power generation system," Applied Sciences, vol. 6, no. 10, 2016. 
[6] M. M. Hashempour, M. Yang, and T. Lee, "An adaptive control of DPWM for clamped-three-level photovoltaic inverters with unbalanced neutral-point voltage," IEEE Transactions on Industry Applications, vol. 66, pp. 6133-6148, 2018.

[7] F. Gao, X. F. Ge, and J. B. Wang, "A single-stage buck-boost three-level neutral-point-clamped inverter for the grid-gied photovoltaic power generation," in Proceedings of the IEEE Energy Conversion Congress Expo (ECCE), pp. 547-553, September 2013.

[8] E. Serban, M. Ordonez, and C. Pondiche, "DC-bus voltage range extension in $1500 \mathrm{v}$ photovoltaic inverters," IEEE Journal of Emerging and Selected Topics in Power Electronics, vol. 3, no. 4, pp. 901-917, 2015.

[9] PVS980 central inverters, ABB, Zurich, Switzerland, http://new .abb.com/power-converters.

[10] J. Kikuchi and T. Lipo, "Three-phase PWM boost-buck rectifiers with power-regenerating capability," IEEE Transactions on Industry Applications, vol. 38, no. 5, pp. 1361-1369, 2002.

[11] F. Gao, P. C. Loh, R. Teodorescu, and F. Blaabjerg, "Diodeassisted buck-boost voltage-source inverters," IEEE Transactions on Power Electronics, vol. 24, no. 9, pp. 2057-2064, 2009.

[12] Y. Zhang, J. Liu, and C. Zhang, "Improved pulse-width modulation strategies for diode-assisted buck-boost voltage source inverter," IEEE Transactions on Power Electronics, vol. 28, no. 8, pp. 3675-3688, 2013.

[13] F. Z. Peng, “Z-source inverter," IEEE Transactions on Industry Applications, vol. 39, no. 2, pp. 504-510, 2003.

[14] S. Dong, Q. Zhang, and S. Cheng, "Analysis of critical inductance and capacitor voltage ripple for a bidirectional Z-source inverter," IEEE Transactions on Power Electronics, vol. 30, pp. 4409-4415, 2015.

[15] M. S. Pilehvar, M. Mardaneh, and A. Rajaei, "Formulation of phase voltage and calculation of its total harmonic distortion in multilevel Z-source inverter," IET Power Electronics, vol. 8, pp. 1509-1518, 2015.

[16] J. Anderson and F. Z. Peng, "Four quasi-Z-Source inverters," in Proceedings of the 39th IEEE Annual Power Electronics Specialists Conference (PESC '08), pp. 2743-2749, Greece, June 2008.

[17] J. Anderson and F. Z. Peng, "A class of quasi-Z-source inverters," in Proceedings of the IEEE Industry Applications Society Annual Meeting (IAS '08), p. 1, 2008.

[18] M. Abbasi, A. H. Eslahchi, and M. Mardaneh, "Two symmetric extended-boost embedded switched-inductor quasi-Z-Ssource inverter with reduced ripple continuous input current," IEEE Transactions on Industrial Electronics, vol. 65, pp. 5096-5104, 2018.

[19] W. Qian, F. Z. Peng, and H. Cha, "Trans-Z-source inverters," IEEE Transactions on Power Electronics, vol. 26, no. 12, pp. 34533463, 2011.

[20] D. Cao, S. Jiang, and Y. Xu, "Low-cost semi-Z-source inverter for single-phase photovoltaic systems," IEEE Transactions on Power Electronics, vol. 26, no. 12, pp. 3514-3523, 2011.

[21] H. Zhou, S. Xiao, G. Yang, and H. Geng, "Modeling and control for a bidirectional buck-boost cascade inverter," IEEE Transactions on Power Electronics, vol. 27, no. 3, pp. 1401-1413, 2012.

[22] W. Mo, F. Blaabjerg, P. C. Loh, and P. Wang, "Trans-Z-source and $\Gamma$-Z-source neutral-point-clamped inverters," IET Power Electronics, vol. 8, no. 3, pp. 371-377, 2015.

[23] O. Husev, R. C. Carlos, R. C. Enrique, V. Dmitri, and S. Serhii, "Single phase three-level neutral-point-clamped quasi-Zsource inverter," IET Power Electronics, vol. 8, pp. 1-10, 2015.
[24] K. Tan, F. Gao, P. C. Loh, and F. Blaabjerg, "Enhanced buckboost neutral-point-clamped inverters with simple capacitivevoltage balancing," IEEE Transactions on Industry Applications, vol. 46, no. 3, pp. 1021-1033, 2010.

[25] H. R. Massrur, T. Niknam, M. Mardaneh, and A. H. Rajaei, "Harmonic elimination in multilevel inverters under unbalanced voltages and switching deviation using a new stochastic strategy," IEEE Transactions on Industrial Informatics, vol. 12, no. 2, pp. 716-725, 2016.

[26] J. Pou, J. Zaragoza, and S. Ceballos, "A carrier-based PWM strategy with zero sequence voltage injection for a three-level neutral-point-clamped converter," IEEE Transactions on Power Electronics, vol. 27, pp. 642-651, 2012.

[27] A. Bendre, G. Venkataramanan, D. Rosene, and V. Srinivasan, "Modeling and design of a neutral-point voltage regulator for a three-level diode-clamped inverter using multiple-carrier modulation," IEEE Transactions on Industrial Electronics, vol. 53, no. 3, pp. 718-726, 2006.

[28] Y. Li, Y. Guo, X. Huangfu, J. Wang, M. Zhang, and W. Liu, "Modeling and control of neutral point voltage balancing for T-type three-level inverters," Electric Power Engineering Technology, vol. 36, pp. 61-65, 2017.

[29] Z. Zhang, O. C. Thomsen, and M. A. E. Andersen, "Discontinuous PWM modulation strategy with circuit-level decoupling concept of three-level neutral-point-clamped (NPC) inverter," IEEE Transactions on Industrial Electronics, vol. 60, no. 5, pp. 1897-1906, 2013.

[30] U. Choi, J. S. Lee, and K. B. Lee, "New modulation strategy to balance the neutral-point voltage for three-level neutralclamped inverter systems," IEEE Transactions on Energy Conversion, vol. 29, pp. 91-100, 2014.

[31] A. K. Gupta and A. M. Khambadkone, "A simple space vector PWM scheme to operate a three-level NPC inverter at high modulation index including over modulation region with neutral point balancing," IEEE Transactions on Industrial Application, vol. 43, pp. 751-760, 2007.

[32] U. Choi, F. Blaabjerg, and K. B. Lee, "Control strategy of two capacitor voltages for separate MPPTs in photovoltaic systems using neutral-point-clamped inverters," IEEE Transactions on Industrial Application, vol. 51, pp. 3295-3303, 2015.

[33] M. Schweizer, T. Friedli, and J. W. Kolar, "Comparative evaluation of advanced three-phase three-level inverter/converter topologies against two-level systems," IEEE Transactions on Industrial Electronics, vol. 60, no. 12, pp. 5515-5527, 2013.

[34] A. Stupar, T. Friedli, J. Minibock, and J. W. Kolar, “Towards a 99\% efficient three-phase buck-type PFC rectifier for 400-V DC distribution systems," IEEE Transactions on Power Electronics, vol. 27, pp. 642-651, 2012.

[35] G. Yin, M. Zhu, Y. Xie, and T. Jiang, "A calculating method for loss and junction temperature of IGBT based on MMC," Electric Power Engineering Technology, vol. 37, pp. 129-133, 2018.

[36] J. Lee and K. Lee, "New modulation techniques for a leakage current reduction and a neutral-point voltage balance in transformerless photovoltaic systems using a three-level inverter," IEEE Transactions on Power Electronics, vol. 29, no. 4, pp. 17201732, 2014.

[37] P. Chen and Y. Lai, "Effective EMI filter design method for three-phase inverter based upon software noise separation," IEEE Transactions on Power Electronics, vol. 25, no. 11, pp. 27972806, 2010. 


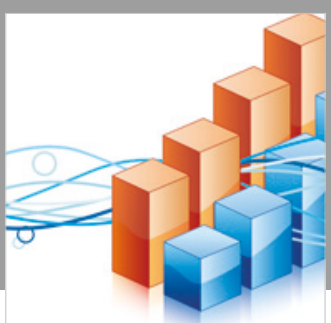

Advances in

Operations Research

\section{-n-m}
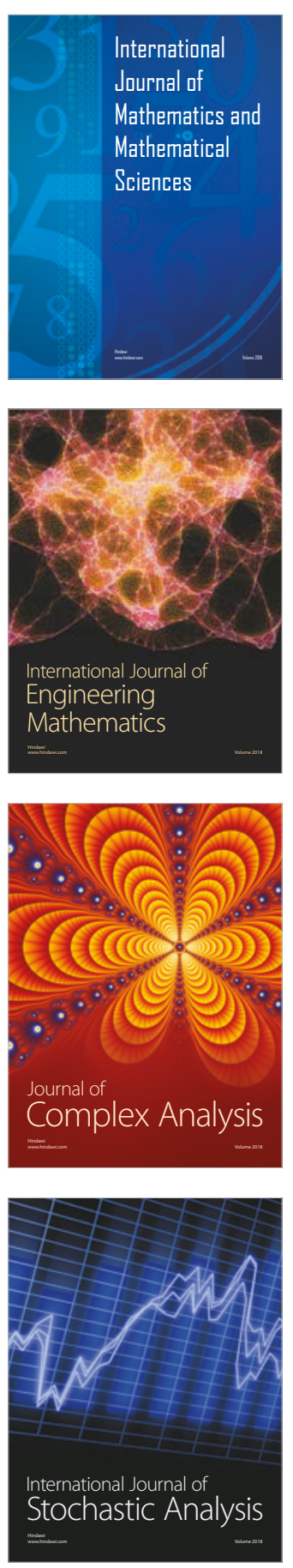
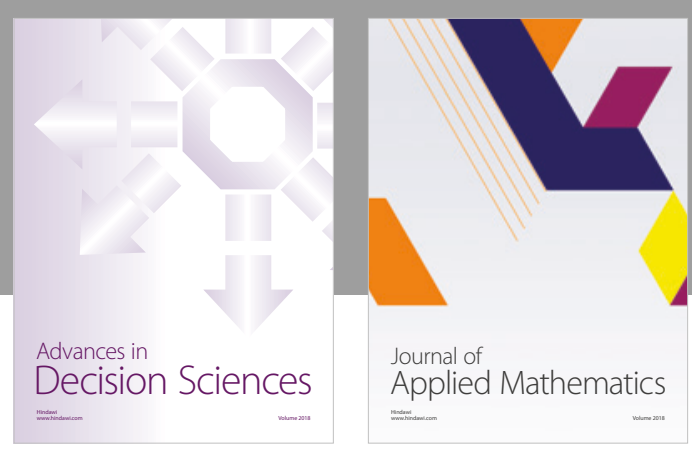

Journal of

Applied Mathematics
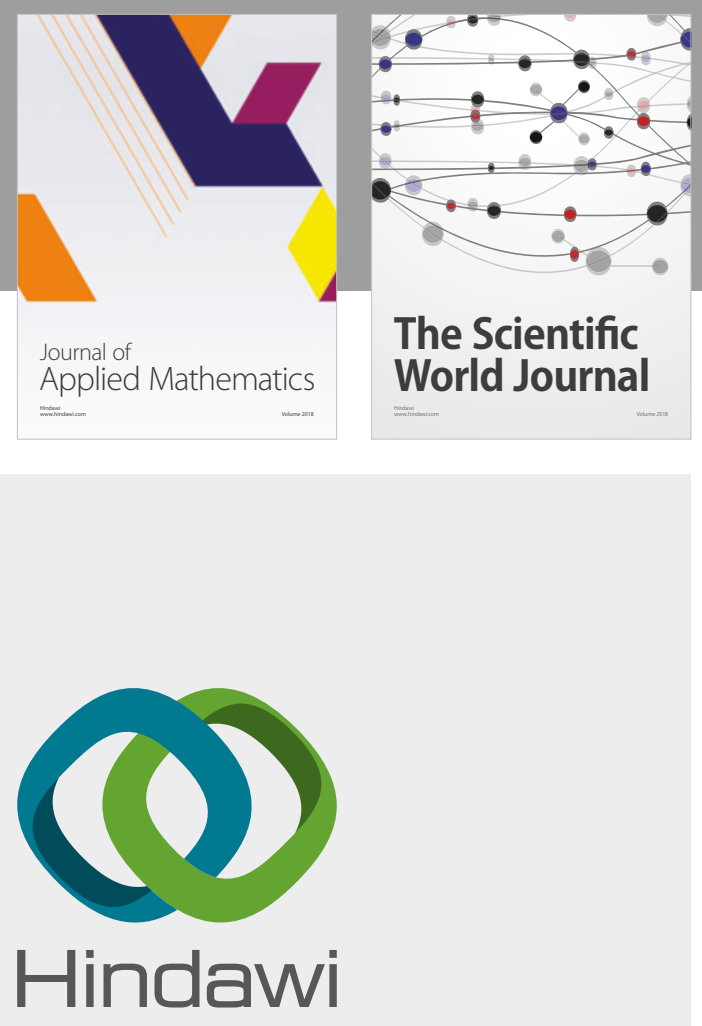

Submit your manuscripts at

www.hindawi.com

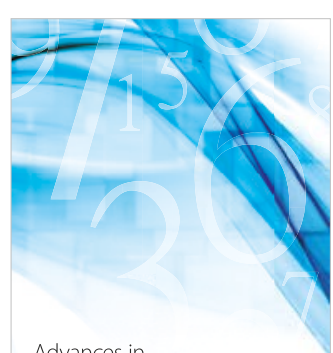

Advances in
Numerical Analysis
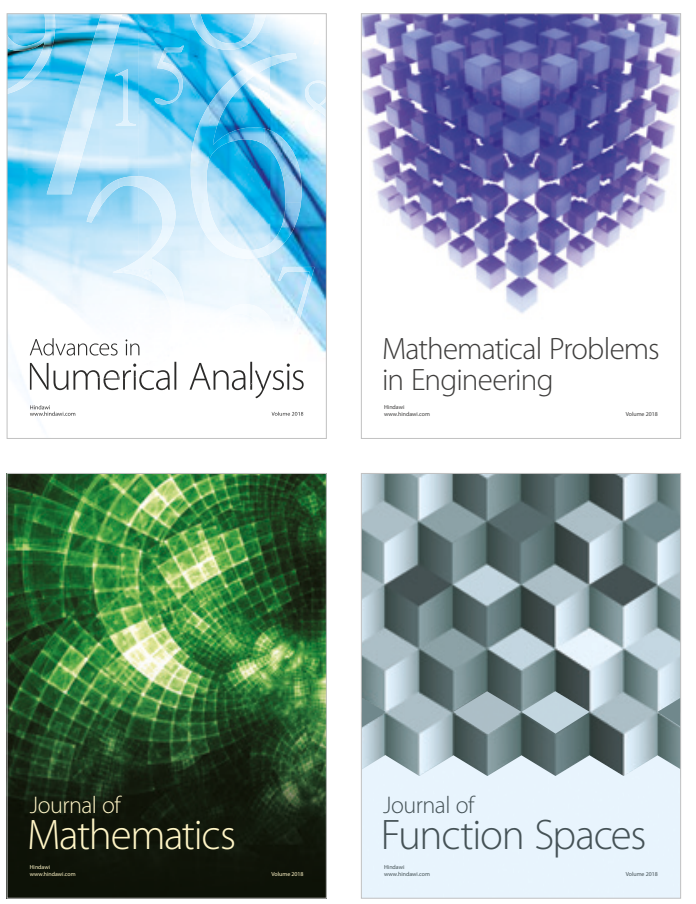

Mathematical Problems in Engineering

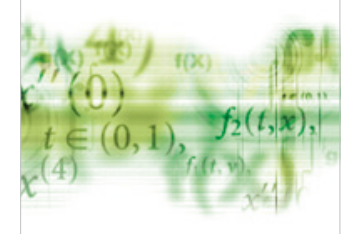

International Journal of

Differential Equations

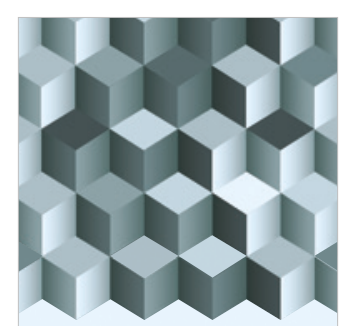

Journal of

Function Spaces

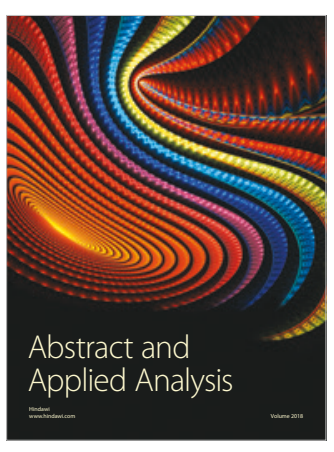

The Scientific

World Journal

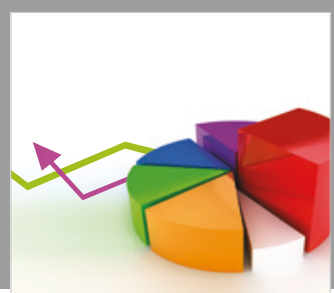

Journal of

Probability and Statistics
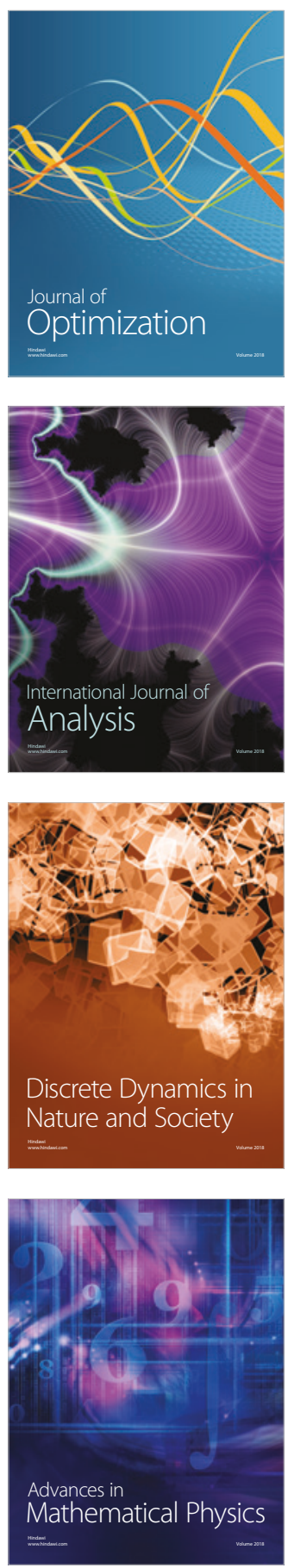